\title{
The Growth and Limits of Arbitrage: Evidence from Short Interest
}

\section{Citation}

Hanson, Samuel G., and Adi Sunderam. "The Growth and Limits of Arbitrage: Evidence from Short Interest." Review of Financial Studies (forthcoming). (Internet Appendix: http:// www.people.hbs.edu/shanson/shortint_IA_20130814_FINAL.pdf)

\section{Permanent link}

http://nrs.harvard.edu/urn-3:HUL.InstRepos:11148066

\section{Terms of Use}

This article was downloaded from Harvard University's DASH repository, and is made available under the terms and conditions applicable to Open Access Policy Articles, as set forth at http:// nrs.harvard.edu/urn-3:HUL.InstRepos:dash.current.terms-of-use\#OAP

\section{Share Your Story}

The Harvard community has made this article openly available.

Please share how this access benefits you. Submit a story.

Accessibility 


\title{
The Growth and Limits of Arbitrage: Evidence from Short Interest
}

\author{
Samuel G. Hanson \\ Harvard Business School \\ Adi Sunderam \\ Harvard Business School \\ August 2013 \\ (First draft: April 2011)
}

\begin{abstract}
We develop a novel methodology to infer the amount of capital allocated to quantitative equity arbitrage strategies. Using this methodology, which exploits time-variation in the cross-section of short interest, we document that the amount of capital devoted to value and momentum strategies has grown significantly since the late 1980s. We provide evidence that this increase in capital has resulted in lower strategy returns. However, consistent with theories of limited arbitrage, we show that strategy-level capital flows are influenced by past strategy returns and strategy return volatility and that arbitrage capital is most limited during times when strategies perform best. This suggests that the growth of arbitrage capital may not completely eliminate returns to these strategies. (JEL G02, G12, G14, G23)

\section{Acknowledgments}

We are grateful to Malcolm Baker, Zahi Ben-David, John Campbell, Sergey Chernenko, Lauren Cohen, Karl Diether, Robin Greenwood, Joel Hasbrouck, David Hirshleifer (the executive editor), Harrison Hong, Jakub Jurek, Johnny Kang, Jonathan Lewellen, Antti Petajisto, Jeff Pontiff, David Scharfstein, Erik Stafford, Laura Starks (the editor), Jeremy Stein, Luis Viciera, Ingrid Werner, an anonymous referee, and seminar participants at Harvard University, the Financial Research Association, the NYU Stern Market Microstructure Conference, Princeton University, and the Western Finance Association Annual Meeting for helpful comments and suggestions. Send correspondence to Samuel G. Hanson, Harvard Business School, Soldiers Field, Boston, MA 02467, USA; telephone: (617) 495-6137. E-mail: shanson@hbs.edu.
\end{abstract}


How effective is the arbitrage mechanism in real-world financial markets? Textbook asset pricing theory is based on the idea that arbitrage capital will quickly flow toward any investment opportunity offering excess risk-adjusted returns, thus rapidly eliminating those excess returns. Set against the textbook theory stands the growing body of literature on limited arbitrage that posits various frictions that may prevent arbitrageurs from fully eliminating asset mispricing. ${ }^{1}$

The importance of these frictions is of particular interest because of the rapid growth of the professional arbitrage industry in recent years. For instance, assets managed by hedge funds exploiting so-called equity market "anomalies"-puzzling patterns in the cross-section of average stock returns, such as the value and momentum effects—grew from \$101 billion in 2000 to \$364 billion at the end of 2009, a compound annual growth rate exceeding 15\%, according to the Lipper TASS Hedge Fund Asset Flows report published quarterly by Thomson Reuters.

If frictions limiting the effectiveness of arbitrage are minor, then the steady growth of arbitrage capital may eventually eliminate the excess returns to strategies that exploit anomalies (Lo 2004; Stein 2009). Conversely, if frictions limiting arbitrage are more severe, they may limit the extent to which anomaly returns can be competed away, even in the long run.

These issues have been studied extensively in the theoretical literature. However, empirical work on the relationship between arbitrage capital and returns has been hindered by a lack of appropriate data. Whereas the quantities of capital allocated to arbitrage strategies are typically the relevant data for assessing the theory, strategy-level capital figures are usually unavailable because data are aggregated to at least the fund level. For instance, to evaluate the effects of increased capital on arbitrage strategy returns, measuring arbitrage capital at the strategy level is crucial. Similarly, the broader asset pricing implications of limited arbitrage will often depend on the extent to which these limits tend to bind simultaneously for many specialized arbitrageurs using a given strategy (Shleifer and Vishny 2011). However, empirical researchers have been forced to test theories about the growth and limits of arbitrage at either the individual stock or fund level. ${ }^{2}$

In this paper, we propose a novel technique to infer the amount of capital allocated to an arbitrage strategy at a given time. We focus on quantitative equity strategies that attempt to exploit

\footnotetext{
${ }^{1}$ See Gromb and Vayanos (2010) and Section 1 for a review of the relevant theoretical literature on limited arbitrage.

${ }^{2}$ See Aragon and Strahan (2012), Ben-David, Franzoni, and Moussawi (2012), and Savor and Gamboa-Cavazos (2011).
} 
the cross-sectional stock return anomalies uncovered by academic finance over the past twenty-five years. These strategies use short sales to construct low- or zero-beta portfolios that generate abnormal risk-adjusted returns or "alpha.” Of course, there is a lively academic debate about whether each of these anomalies truly represent alpha for diversified investors or whether they are instead compensation for other priced risk factors (i.e., they are compensation for some omitted "beta"). We take no stand on this issue and simply adopt the consensus interpretation of the quantitative equity investors whose behavior we seek to study: they believe that these anomalous return patterns do indeed represent alpha.

Prior work has documented that short-sellers appear to exploit prominent anomaly strategies, including book-to-market and other value signals (Dechow et al. 2001), accruals (Hirshleifer, Teoh, and Yu 2011), and post-earnings-announcement drift (Cao et al. 2007). However, little is known about how the amount of arbitrage capital devoted to these strategies has evolved over time. This paper aims to fill the gap. We study the evolution of arbitrage capital over time and document relationships between the quantity of arbitrage capital and strategy returns.

Our key insight is that each cross-section of short interest reveals how intensely arbitrageurs are using a quantitative equity strategy at a given time. For instance, when short interest is especially weighted toward growth stocks, we should infer that more arbitrage capital is being devoted to value strategies. We formalize this idea in a regression setting. We run cross-sectional regressions explaining stock-level short interest and show that the coefficients from these regressions can be interpreted as proxies for strategy-level arbitrage capital. We first ask whether variation in our measure is driven by changes in arbitrageur demand to short stocks or changes in share lending supply. Using data on institutional ownership as a proxy for share-lending supply, we argue that changes in our strategy-level capital measures are not driven solely by shifts in sharelending supply—shifts in shorting demand appear to have played an important role as well.

Our basic methodological contribution-using the cross-section of positions to infer the allocation of arbitrage capital across strategies_-is quite general and can be applied in any setting in which aggregated position-level data is available to researchers, practitioners, or regulators. However, several factors make stock-level short interest an excellent setting in which to use this 
more general empirical strategy. First, equity short sellers are typically sophisticated investors. ${ }^{3}$ And, consistent with this observation, a number of papers show that short interest negatively predicts stock returns in the cross-section (see, e.g., Asquith, Pathak, and Ritter (2005); Cohen, Diether, and Malloy (2007)). Second, because of the costs of short selling stocks, short positions are likely put on by managers who are actively seeking alpha. Finally, short interest data may be more informative than data on long-side stock holdings because, in the aggregate, long-side institutional investors hold the market portfolio and show little tendency to bet on characteristics known to predict stock returns in the cross-section (Lewellen 2011). In other words, any long-side analysis must screen out the large number of institutions that passively index; otherwise, it will have little power to detect time variation in arbitrage capital.

We primarily focus on the value and momentum strategies because of their long histories among both academics and practitioners. We first use our capital measures to explore lowfrequency trends in arbitrage capital. We show that short-side capital in both strategies has increased dramatically, particularly since the early 2000s. Using institutional ownership as a proxy for lendable share supply (D’Avolio 2002; Nagel 2005; Hirshleifer, Teoh, and Yu 2011), we then ask whether these trends are driven by an increase in shorting demand or an expansion of share lending supply. We find similar upward trends in short interest when we focus only on stocks with high institutional ownership, which are less likely to have experienced a significant easing of supply constraints. Thus, we argue that increases in shorting demand have played an important role in driving these long-term trends. We obtain similar results when we extend this analysis to other anomaly strategies, such as accruals, post-earnings-announcement drift, and share issuance.

We then explore the asset-pricing implications of the growth of arbitrage capital over the past twenty-five years. We provide evidence that the increasing level of arbitrage capital has been associated with a reduction in the returns that these anomaly strategies deliver. In combination with the cuts on institutional ownership mentioned above, these findings provide suggestive evidence that, in the time series, increases in shorting demand may have contributed to the declining

\footnotetext{
${ }^{3}$ Boehmer, Jones, and Zhang (2012) and Ben-David, Franzoni, and Moussawi (2012) argue that hedge funds account for most short interest in the United States. According to Goldman Sachs (2008), hedge funds account for 85\% of short interest.
} 
profitability of anomaly strategies. ${ }^{4}$ In addition, we find evidence that the growth in arbitrage capital has been associated with a more rapid time decay of anomaly signals. Specifically, the alpha associated with these strategies is now typically eliminated only a few months after portfolio formation.

Does the association between higher arbitrage capital and lower returns mean that the growth of capital will eventually eliminate the abnormal returns to these strategies? Not necessarily. As pointed out by Shleifer and Vishny (1997), frictions limiting arbitrage may allow positive abnormal returns to persist, even in the face of substantial arbitrage capital. For instance, to solve agency or informational problems, delegated arbitrageurs may be forced to invest a substantial fraction of their personal wealth in the funds they manage, leaving them with large undiversified exposures to strategy-specific risks. Thus, in equilibrium they may need to earn positive abnormal returns to compensate for these risks. In other words, we should expect a tight connection between the extent to which frictions impede real-world arbitrage in the short run and the persistence of anomaly returns over the longer run.

Thus, to gain additional insight into whether anomaly returns are likely to persist over the long run, we ask whether the data are consistent with meaningful strategy-level limits to arbitrage. Although we are limited in our ability to isolate precise mechanisms, we find evidence consistent with the idea that the arbitrage mechanism is at times far from perfect. We first study the relationship between strategy-level capital flows and past strategy returns. We find a positive performance-flow relationship for momentum. After low returns, capital tends to flow out of momentum strategies. Furthermore, we find that capital flows into both value and momentum negatively forecast future strategy returns. Conversely, both strategies suffer outflows at times when future returns will be high, consistent with limits to arbitrage.

We then explore the relationship between arbitrage capital and proxies for funding or leverage constraints. For both value and momentum, we find that strategy-level capital tends to decline following increases in strategy volatility. We also find that capital exits momentum when other arbitrage strategies do poorly and when the Treasury Eurodollar spread widens. Although the

\footnotetext{
${ }^{4}$ This distinguishes our findings from those of Nagel (2005) and Hirshleifer, Teoh, and Yu (2011). Those authors argue that, in the cross-section, limited shared-lending supply contributes to the profitability of anomaly strategies.
} 
evidence is by no means definitive, one possible explanation for these findings is that multistrategy arbitrageurs choose to liquidate momentum positions to meet capital redemptions or margin calls. Overall, our findings suggest that quantitative equity arbitrage suffers from the limits discussed in the theoretical literature. This is consistent with the idea that specialized quantitative equity arbitrageurs may bear significant amounts of undiversifiable risk, potentially limiting the extent to which these anomalies can be arbitraged away in the long run.

This paper is organized as follows. Section 1 develops a conceptual framework for the analysis. Section 2 describes the data. Section 3 introduces our methodology for measuring strategylevel arbitrage capital and discusses trends in capital since 1988. Section 4 presents our results on the asset-pricing feedback between capital and strategy returns. Section 5 concludes.

\section{Conceptual Framework}

In this section, we begin by presenting a brief model to motivate our measure of anomaly-strategy arbitrage capital. We then review the literature on the evolution and limits of arbitrage in order to develop a series of additional testable asset-pricing predictions that we can take to the data.

\subsection{Model}

In the model, most agents hold slightly incorrect beliefs about expected stock returns and a small group of agents, called short-sellers, hold correct beliefs. We validate our empirical methodology in this setup, showing that a cross-sectional regression of short interest on an anomaly signal that proxies for mispricing uncovers the number of short-sellers using that signal.

Let stocks be indexed by $i=1,2, \ldots, N$, and suppose that each stock has fixed supply $w_{i}$, where $\sum_{i=1}^{N} w_{i}=1$. At time $t$, assume that fraction $\kappa_{t}$ of stock investors are short-sellers who use the anomaly signal and thus have correct beliefs about future returns. A fraction $\left(1-\kappa_{t}\right)$ of investors ignore the anomaly signal and therefore have slightly incorrect beliefs. Specifically, short-sellers correctly believe that the expected excess returns on stock $i$ are $E_{t}^{*}\left[r_{i t+1}\right]$, whereas other investors incorrectly believe that

$$
E_{t}\left[r_{i t+1}\right]=E_{t}^{*}\left[r_{i t+1}\right]+\delta_{i t} .
$$

Thus, $\delta_{i t}$ represents the overpricing of stock $i$ at time $t$. We treat $\delta_{i t}$ as exogenously given and 
assume that it is an observable anomaly signal. For instance, think of the market-to-book ratio $(M / B)_{i t}$ as $\delta_{i t}$ for the value strategy.

We first solve for the true excess returns that short-sellers expect in equilibrium, $E_{t}^{*}\left[r_{i t+1}\right]$. For simplicity, we assume that the anomaly is not associated with aggregate mispricing, so $\sum_{i=1}^{N} w_{i} \delta_{i t}=0$. This implies that $E_{t}^{*}\left[r_{M, t+1}\right]=E_{t}\left[r_{M, t+1}\right]$, where $r_{M, t+1}=\sum_{i=1}^{N} w_{i} r_{i, t+1}$ is the excess return on the market portfolio. In other words, we assume that short-sellers who use the anomaly signal and other investors who do not expect the same excess return on the market portfolio; they simply disagree about expected returns in the cross-section. Furthermore, we assume that shortsellers and other investors perceive the same exogenously, given the variance-covariance matrix of returns. These assumptions simplify the analysis but also capture the focus of quantitative equity investors on the cross-section of expected stock returns. Using vector notation for compactness, our assumptions can be written as $E_{t}\left[\mathbf{r}_{t+1}\right]=E_{t}^{*}\left[\mathbf{r}_{t+1}\right]+\boldsymbol{\delta}_{t}, \operatorname{Var}_{t}\left[\mathbf{r}_{t+1}\right]=\operatorname{Var}_{t}^{*}\left[\mathbf{r}_{t+1}\right]$ and $\mathbf{w}^{\prime} \boldsymbol{\delta}_{t}=0$.

Suppose that both short-sellers and other investors have risk tolerance $\tau$ and maximize mean-variance utility over tomorrow's wealth. Then asset demands of short-sellers are $\mathbf{q}_{s, t}=\tau\left(\operatorname{Var}_{t}^{*}\left[\mathbf{r}_{t+1}\right]\right)^{-1} E_{t}^{*}\left[\mathbf{r}_{t+1}\right]$, whereas those of other investors are $\mathbf{q}_{O, t}=\tau\left(\operatorname{Var}_{t}^{*}\left[\mathbf{r}_{t+1}\right]\right)^{-1}\left(E_{t}^{*}\left[\mathbf{r}_{t+1}\right]+\boldsymbol{\delta}_{t}\right)$.

To clear the market, we require $\mathbf{w}=\kappa_{t} \mathbf{q}_{s, t}+\left(1-\kappa_{t}\right) \mathbf{q}_{O, t}$, which implies that

$$
\begin{aligned}
E_{t}^{*}\left[\mathbf{r}_{t+1}\right] & =-\left(1-\boldsymbol{\kappa}_{t}\right) \boldsymbol{\delta}_{t}+\frac{\operatorname{Cov}_{t}^{*}\left[\mathbf{r}_{t+1}, r_{M, t+1}\right]}{\operatorname{Var}_{t}^{*}\left[r_{M, t+1}\right]} E_{t}^{*}\left[r_{M, t+1}\right] \\
& =\boldsymbol{\alpha}_{t}+\boldsymbol{\beta}_{t} E_{t}^{*}\left[r_{M, t+1}\right],
\end{aligned}
$$

where $\boldsymbol{\alpha}_{t}=-\left(1-\kappa_{t}\right) \boldsymbol{\delta}_{t}$ is CAPM “alpha” and $\boldsymbol{\beta}_{t}=\operatorname{Cov}_{t}^{*}\left[\mathbf{r}_{t+1}, r_{M, t+1}\right] / \operatorname{Var}_{t}^{*}\left[r_{M, t+1}\right]$ is CAPM "beta." Thus, Equation (2) implies that expected excess returns in the model are described by a conditional CAPM with time-varying alphas. For simplicity, we also assume that $\operatorname{Cov}_{t}\left[\delta_{i t}, \beta_{i t}\right]=0$ so that there is no systematic relationship in the model between CAPM alpha and CAPM beta. ${ }^{5}$

\footnotetext{
5 This is arguably counterfactual: work on the low- $\beta$ anomaly, including Black (1973), Ang et al. (2006), Baker and Wurgler (2006), Frazzini and Pedersen (2011), Hong and Sraer (2012), and many others, suggests that low- $\beta$ stocks have high $\alpha$ s and that high- $\beta$ stocks have low $\alpha$, that is, that the security market line is "too flat." We make this assumption to simplify the analysis, but the basic results would go through without it.
} 
This implies that the total positions of short-sellers in equilibrium are given by $\kappa_{t} \mathbf{q}_{s, t}^{*}=\kappa_{t} \mathbf{w}-\kappa_{t}\left(1-\kappa_{t}\right) \tau\left(\operatorname{Var}_{t}^{*}\left[\mathbf{r}_{t+1}\right]\right)^{-1} \boldsymbol{\delta}_{t}$. To express these positions as short interest ratios, we multiply by -1 and scale by market capitalization, yielding

$$
\mathbf{S R}_{t}^{*}=-\kappa_{t} \mathbf{q}_{S, t}^{*} \cdot / \mathbf{w}=\kappa_{t}\left(1-\kappa_{t}\right) \tilde{\boldsymbol{\delta}}_{t}-\kappa_{t} \mathbf{1}
$$

where $\tilde{\boldsymbol{\delta}}_{t}=\left[\tau\left(\operatorname{Var}_{t}^{*}\left[\mathbf{r}_{t+1}\right]\right)^{-1} \boldsymbol{\delta}_{t} . / \mathbf{w}\right]$ is a linear transformation of $\boldsymbol{\delta}_{t \cdot}{ }^{6}$ Loosely speaking, all else equal, short interest in stock $i$ is higher when stock $i$ is more mispriced ( $\delta_{i t}$ is higher) and lower when the stock $i$ is more volatile or a larger part of the market portfolio.

As explained above, we interpret $\delta_{t}$ as an equity anomaly signal to short a given stock. We use the model to derive four main results that we prove in the Internet Appendix. The first two results describe equilibrium expected returns and short interest, given by Equations (2) and (3) above, respectively.

Result 1: The anomaly signal, $\delta_{i t}$, negatively forecasts returns in each cross-section.

Result 2: Higher short-interest is associated with lower returns in each cross-section.

Result 1 follows from the fact that most investors are too optimistic about stocks with high $\delta_{\text {it }}$ and bid up their prices too much. Because short sellers have limited risk tolerance, they do not push prices all the way back to fundamental value. Result 2 is intuitive and simply says that arbitrageurs most heavily short the most overpriced stocks.

The third result is the key to understanding our empirical measure of arbitrage capital.

Result 3: A cross-sectional regression of short interest on the anomaly signal recovers information about the amount of arbitrage capital devoted to the signal.

Intuitively, when there are more short sellers, the difference in short interest between overvalued and undervalued stocks will be larger. Formally, the coefficient from a cross-sectional regression on short interest on the anomaly signal is given by

$$
\kappa_{t}^{S R}=\frac{\operatorname{Cov}_{t}\left[\delta_{i t}, S R_{i t}^{*}\right]}{\operatorname{Var}_{t}\left[\delta_{i t}\right]}=\kappa_{t}\left(1-\kappa_{t}\right) \frac{\operatorname{Cov}_{t}\left[\delta_{i t}, \tilde{\delta}_{i t}\right]}{\operatorname{Var}_{t}\left[\delta_{i t}\right]}>0,
$$

which is increasing in $\kappa_{t}$ so long as $\kappa_{t}<1 / 2$, that is, as long as sophisticated short sellers are not the

\footnotetext{
${ }^{6}$ Saying $S R_{i t}^{*}=\max \left\{-\kappa_{t} q_{S, i t}^{*} / w_{i t}, 0\right\}$ is more accurate, but we ignore this truncation problem for simplicity.
} 
majority of the market. ${ }^{7}$ Moreover, the regression coefficient is approximately linear in $\kappa_{t}$ for small $\kappa_{t}$. Thus, our empirical procedure, which runs cross-sectional regressions of short interest on anomaly signals, will accurately measure the amount of arbitrage capital so long as arbitrageurs are not too large relative to the overall market.

Finally, our fourth result formally derives a relationship between our measure of arbitrage capital and returns that we will look for in the data.

Result 4: Our cross-sectional regression-based measures of arbitrage capital should negatively forecast long-short anomaly returns in the time series.

Intuitively, the expected returns on a long-short strategy using signal $\delta_{i t}$ are lower when more arbitrage capital is devoted to the signal. When there are more short-sellers using the signal, they arbitrage away more of the mispricing at time $t$, so there is less return predictability at $t+1$. Because Result 3 shows that we can recover the amount of arbitrage capital from cross-sectional short interest regressions, Result 4 follows naturally.

\subsection{Testable predictions}

The model provides formal motivation for our measure of arbitrage capital. We now review the literature on the evolution and limits of arbitrage to develop the full set of testable asset-pricing predictions, which we will take to the data.

1.2.1 Evolution of arbitrage: Long-term trends. Textbook asset-pricing theory is based on the idea that arbitrage capital will quickly flow toward any investment opportunity that, in expectation, offers excess risk-adjusted returns or alpha to well-diversified investors. In the textbook treatment, markets are always in or very near the steady state at which expected alpha is zero. Thus, barring changes in transaction costs or in the factors that give rise to anomalies (e.g., investor underreaction to new information), the amount of arbitrage capital dedicated to a particular anomaly strategy should not vary significantly over time. In practice, however, investors' awareness of the

\footnotetext{
${ }^{7}$ We need $\kappa_{t}<1 / 2$ because increasing $\kappa_{t}$ has two effects. First, it increases the amount of short-seller capital that can be brought to bear on a given mispricing, increasing the cross-sectional correlation between $\delta_{\text {it }}$ and short interest. Second, it reduces the latent mispricing because a smaller fraction of investors now have mistaken beliefs. This reduces the need for informed arbitrageurs to short in the first place, decreasing the cross-sectional correlation between $\delta_{i t}$ and short interest. For $\kappa_{t}<1 / 2$, the initial effect dominates, whereas the latter effect dominates for $\kappa_{t}>1 / 2$.
} 
profitability of anomaly strategies may have risen over time, and market institutions and infrastructure may have evolved in ways that allow these strategies to be exploited more easily.

A small, but emerging, body of theoretical literature asks how the amount of arbitrage capital devoted to various strategies (or to various markets) should evolve over time. A common prediction is that arbitrageurs should allocate capital toward strategies that earn excess risk-adjusted returns. However, because of various frictions, capital may only gradually flow toward strategies that generate alpha. First, learning may be costly and gradual, slowing the diffusion of information about strategy alpha (Duffie and Strulovici 2012; Duffie and Manso 2007; Duffie, Malamud, and Manso 2009; McLean and Pontiff 2012). Second, time-to-build problems may limit the speed at which investors can set up arbitrage vehicles (i.e., specialized hedge or mutual funds) to exploit specific anomalies (Hanson and Sunderam 2013). Therefore, a natural prediction is that the amount of arbitrage capital devoted to equity anomaly strategies has risen over past twenty-five years.

Prediction 1. Arbitrage capital devoted to equity anomaly strategies has risen over time.

If this prediction is correct, then Result 4 shows that we would expect higher levels of arbitrage capital to attenuate excess risk-adjusted strategy returns. Similarly, Stein (2009) models the entry decisions of arbitrageurs and shows that expected anomaly returns should decline as aggregate arbitrageur risk tolerance rises. McLean and Pontiff (2012) provide empirical evidence consistent with this hypothesis, showing that anomaly returns tend to decline after the publication of academic articles documenting their existence.

Prediction 2. As capital devoted to anomalies rises, expected returns to anomaly strategies decline.

An increase in the amount of arbitrage capital devoted to an anomaly strategy might also impact the rate at which the profitability of the signal decays following initial portfolio formation. Specifically, a large number of equity anomalies, such as momentum, post-earnings-announcement drift, accruals, and net share issuance, are often thought to reflect some form of investor underreaction to new information. ${ }^{8}$ According to this view, quantitative equity investors are

\footnotetext{
${ }^{8}$ For instance, investor underreaction might stem from a conservatism bias and use of a representativeness heuristic as in Barberis, Shleifer, and Vishny (1998), a combination of overconfidence and biased self-attribution as in Daniel, Hirshleifer, and Subrahmanyam (1998), or limited attention and bounded rationality as in Hong and Stein (1999).
} 
specialists who have developed a systematic procedure for identifying value-relevant information that other investors tend to underweight. As more arbitrage capital flows into anomaly strategies, one would expect this information to be impounded into market prices more rapidly, leading the profitability of anomaly signals to decay more rapidly following portfolio formation (Hong and Stein 1999).

Prediction 3. As capital devoted to anomalies rises, profitability of anomaly signals decays more rapidly following initial portfolio formation.

\subsubsection{Limits of arbitrage: Short-term feedback between returns and capital flows. Of course,}

the literature on limited arbitrage suggests that, despite the growth of arbitrage capital, arbitrageurs may not be able to completely eliminate the excess returns to anomaly strategies in the long run. The key idea is that arbitrage requires a significant degree of specialization. As noted by Holmstrom (1979), there is frequently a trade-off between insuring a specialized agent and incentivizing him to exert effort. In the context of arbitrage, this implies that specialized arbitrageurs must often retain significant exposures to idiosyncratic strategy-level risks associated with anomaly arbitrage (e.g., the risk that prices temporarily move in an unfavorable direction, leading to a withdrawal of arbitrage capital and substantial personal losses for arbitrageurs). ${ }^{9}$ To compensate them for such risks, arbitrageurs must expect to earn positive abnormal returns, implying that anomaly excess returns may persist in the long run. ${ }^{10}$

Although the theoretical literature has posited a variety of specific frictions that could limit arbitrage, one common theme is that arbitrageurs' access to capital may be limited at certain times, for instance, when volatility has increased or past performance has been poor. Thus, to explore whether the data are consistent with significant limits to arbitrage, we examine relationships between changes in arbitrage capital (i.e., capital flows) and returns. In contrast, the predictions outlined above in Section 1.2.1 concerning the growth of arbitrage capital involve the relationship

\footnotetext{
${ }^{9}$ Holmstrom and Tirole (1997), Gabaix, Krishnamurthy, and Vigneron (2007), and He and Krishnamurthy (2013) develop formal models of the asset pricing implications that follow when specialized arbitrageurs are forced to bear significant amounts of idiosyncratic risk.

${ }^{10}$ Frictions limiting arbitrage may amplify volatility and thus make arbitrage riskier than it would otherwise be for specialists, leading to the "create space" effect of DeLong et al. (1990). Undiversified specialists must earn a risk premium for undertaking these risky strategies, but this risk premium looks like alpha when judged from the perspective of generalist investors who are unable to costlessly implement these strategies.
} 
between the level of arbitrage capital and strategy returns.

The theoretical work on limits to arbitrage can be divided into two strands. The first strand, including Shleifer and Vishny (1997), Gromb and Vayanos (2010), and Stein (2009), introduces agency or informational problems that lead investors to withdraw equity capital from arbitrageurs following poor returns. ${ }^{11}$ However, as Stein (2009) notes, the key predictions in such models may vary by strategy. For strategies that have a "fundamental anchor", that is, an observable signal of the strategy's future expected profitability, investors should understand that poor current returns are likely to be associated with high future returns and thus should rationally increase their strategy capital allocation following poor strategy returns. For strategies without a fundamental anchor, however, a positive performance-flow relationship may limit the ability of arbitrageurs to take large positions precisely when their investment opportunities are most attractive.

Prediction 4. There is a positive performance-flow relationship for strategies without fundamental anchors. However, the performance-flow relationship should be attenuated and possibly even reversed for strategies with a fundamental anchor.

Existing empirical work has focused on individual mutual and hedge funds and has documented a positive performance-flow relationship at the individual fund level. ${ }^{12}$ Recent work documents a positive performance-flow relationship at the individual stock level and fund level in the context of the financial crisis. For instance, Ben-David, Franzoni, and Moussawi (2012) show that investor redemptions forced hedge funds to sell a large fraction of their equity holdings, and Cella, Ellul, and Giannetti (2011) show that stocks held by short-term investors, defined as those with high portfolio turnover, suffered larger declines in the aftermath of the Lehman default.

For strategies in which there is a positive performance-flow relationship, there is scope for spillovers across strategies (see, e.g., Kiyotaki and Moore (1997); Fostel and Geanokoplos (2008); Duffie and Strulovici (2012)). If arbitrageurs use multiple strategies, poor performance of one strategy can lead to investor withdrawals, forcing arbitrageurs to reduce the amount of capital they

\footnotetext{
${ }^{11}$ Whereas Shleifer and Vishny (1997) take a positive performance-flow relationship as given, Barberis and Shleifer (2003) and Berk and Green (2004) microfound the relationship as the result of irrational performance chasing and rational updating about fund manager ability, respectively.

${ }^{12}$ Chevalier and Ellison (1997) and Sirri and Tufano (1998) find a positive, convex performance-flow relationship for mutual funds. Ding et al. (2009) find that the relationship for hedge funds is also positive and convex in the absence of share restrictions but that the relationship becomes concave in the presence of restrictions.
} 
allocate to other strategies. Boyson, Stahel, and Stulz (2010) provide indirect evidence of contagion at the strategy level, showing that significantly negative return events are more highly correlated across hedge fund strategies than one would otherwise expect. At the individual stock level and fund level, Hau and Lai (2012) document a similar type of contagion in the context of the recent financial crisis, showing that nonfinancial stocks held by mutual funds with large exposures to financial stocks did poorly after the Lehman default.

Prediction 5. To the extent that anomalies are exploited by "multistrategy" arbitrageurs, poor returns in other arbitrage strategies should lead to declines in strategy capital.

The second strand of theoretical papers that study the limits of arbitrage focuses on funding and leverage constraints. The frictions in these papers deprive arbitrageurs of debt capital at particular times: the funding constraints are driven by financial intermediaries that provide leverage to arbitrageurs rather than outside investors who provide them with equity capital. In many of these papers, including Brunnermeier and Pedersen (2009), Brunnermeier and Sannikov (2012), and Geanakoplos (2010), increases in asset price volatility lead to binding funding constraints. Thus, we would expect to see higher volatility associated with lower strategy-level arbitrage capital. ${ }^{13}$

The balance sheet strength of financial intermediaries may be another key driver of arbitrageur funding constraints, as pointed out by Brunnermeier and Pedersen (2009), Garleanu and Pedersen (2011), Geanakoplos (2010), and Frazzini and Pedersen (2011). We should therefore expect to see strategy-level arbitrage capital decline when proxies for intermediary financial stress are high. Using proprietary data on a sample of hedge funds, Ang, Gorovyy, and van Inwegen (2011) find evidence that the leverage provided to those hedge funds declines as the VIX and the TED spread rise during the financial crisis. ${ }^{14}$ Relatedly, Nagel (2012) argues that the returns to short-term reversal strategies, interpreted by him as a proxy for liquidity provision, increase with

\footnotetext{
${ }^{13}$ Because strategy-level volatility is persistent, standard mean-variance considerations would lead to a similar prediction. Specifically, a rational arbitrageur would forecast high future volatility for strategy $s$ if past volatility has been high, and if he has a short performance horizon, this would lead him to reduce his allocation to strategy s. Without detailed microdata on hedge fund leverage and margins, we cannot distinguish between the funding liquidity story and the more standard mean-variance story. However, we can verify their common prediction.

${ }^{14}$ The Chicago Board Options Exchange Market Volatility Index, or "VIX", is a measure of the implied volatility of S\&P 500 index options. The Treasury Eurodollar spread, or "TED spread", is the difference between a popular threemonth interbank lending rate (LIBOR) and the three-month Treasury bill rate. Both the VIX and the TED spread are frequently used as empirical proxies for the aggregate level of financial intermediary distress.
} 
the VIX, suggesting that liquidity providers face funding constraints when the VIX is high.

Prediction 6. Increases in strategy volatility lead to a reduction in the equilibrium amount of capital devoted to a given anomaly. Similarly, binding financial constraints and increases in intermediary funding costs should lead to declines in strategy-level arbitrage capital.

A final prediction that is common to all theories on limited arbitrage is that frictions lead arbitrageurs to effectively "mistime” strategy-level returns. Constraints become binding at exactly the time that arbitrageurs would like to invest most in a given strategy. This suggests that capital outflows should forecast higher future strategy returns.

Prediction 7. In the presence of significant limits to arbitrage, current capital outflows predict high future strategy returns.

Notably, although we have framed these predictions in terms of arbitrage frictions, as is common in the literature, our empirical methodology simply uncovers the amount of arbitrage capital allocated toward a particular anomaly strategy. The patterns we document are consistent with frictional interpretations, but there may be alternative explanations. Specifically, we cannot observe arbitrageur perceptions, so we cannot rule out the possibility that our results are generated by shifting arbitrageur expectations of returns. For instance, models in which frictional constraints on arbitrage increase following poor or volatile performance deliver many of the same predictions as models in which professional arbitrageurs have extrapolative beliefs.

\section{Data}

We now describe the data used in our analysis, before turning to our methodology for measuring arbitrage capital. In our main analysis, we use monthly data on short interest from June 1988 through December 2011. Short interest data for NYSE and AMEX stocks is obtained from Compustat. For NASDAQ stocks, short interest data is only available from Compustat beginning in July 2003, so we obtain data directly from the exchange prior to this date. ${ }^{15}$ Short interest for stock $i$ in month $t, S H O R T_{i t}$, is the total number of uncovered shares sold short for transactions settling on

\footnotetext{
${ }^{15}$ Compustat's short interest data is from FT Interative and extends back to January 1973 for NYSE- and AMEX-listed stocks, which we use to construct a long time series of arbitrage activity. NASDAQ short interest data is only available beginning in June 1988. NASDAQ does not have short interest data for February and July 1990.
} 
or before the 15th of the month. To form short interest ratios, we normalize short interest by total shares outstanding from CRSP: $S R_{i t}=S H O R T_{i t} / S H R O U T_{i t}$. Assuming that short interest reflects the positions of arbitrageurs, $S R_{i t}$ is the appropriate measure for understanding the impact of sophisticated arbitrageurs because it captures the incremental share supply that must be held by less sophisticated investors. ${ }^{16}$

Two trends in the short interest data deserve mention. First, Figure 1 shows that aggregate short interest rose significantly during our 1988 to 2011 sample on both an equal- and valueweighted basis. Short interest ratios trended upward during the mid-1990s, declined somewhat during the technology bubble as noted by Lamont and Stein (2004), and rose dramatically from 2001 to 2007. Large swings in short interest are observed during the financial crisis from 2007 to 2009, registering a marked drop in August 2007, presumably due to the "quant meltdown” (see Khandani and Lo (2007); Pedersen (2009)), and in September 2008, when the SEC imposed a partial ban on short sales for financial stocks. ${ }^{17}$ Aggregate short interest levels stabilized from 2009 to 2011.

Second, short interest among small stocks has surged since 2000. In fact, the entire crosssectional relationship between firm size and short interest has shifted dramatically. In Figure 2 we plot average short interest ratios by NYSE size decile at six different years in our sample. Short interest ratios for firms in size deciles 2 through 5 have risen sharply since 1999, all hovering near 10\% at year-end 2007. Average short interest for size decile 1 has also grown but lags behind that for non-micro-cap stocks. By contrast, short interest for size decile 10 has been remarkably stable. Although we will show that quantitative equity signals are associated with significant differences in short interest, the growth of quantitative equity arbitrage does not appear to completely explain the broad surge in short interest among small stocks witnessed over the past decade. ${ }^{18}$

\footnotetext{
${ }^{16}$ We winsorize $S R_{i t}$ at the 99.5\%-tile in each cross-section to limit errors caused by disagreements between CRSP and our short interest data on the exact timing of share splits. See Savor and Gamboa-Cavazos (2011) for more on this point.

${ }^{17}$ On September 19, 2008, the Securities and Exchange Commission adopted an emergency order that temporarily banned most short sales in over 900 financial stocks. However, Figure A.3 in the Internet Appendix shows that short interest ratios declined for both nonfinancial and financial firms following the imposition of the ban. Boehmer, Jones, and Zhang (2012) provide a detailed examination of the impact of the 2008 short sales ban.

${ }^{18}$ Possible explanations include the rapid growth of nonquantitative hedge funds, the expansion of institutional sharelending programs, the growth of the prime-brokerage, and advances in information technology.
} 
We supplement the short interest data with data on stock characteristics from CRSP and Compustat, including size $(M E)$ deciles, book-to-market $(B / M)$ deciles, and past twelve-month return deciles (i.e., “momentum” deciles). All cross-sectional deciles are based on NYSE breakpoints. We also compute the fraction of shares held by $13-\mathrm{F}$ institutions as of the most recent quarter-end, the three-month moving average of share turnover (volume over shares outstanding), trailing twelve-month return volatility, exchange dummies (i.e., a NASDAQ dummy and an NYSE dummy), and a dummy that indicates whether a firm has convertible securities outstanding. All continuous variables are winsorized in each cross-section at the $0.5 \%$ and $99.5 \%$-tiles. Table 1 provides detailed definitions of and lists summary statistics for the variables used in the paper.

\section{Measuring the Evolution of Arbitrage Capital}

In this section, we describe our methodology for measuring strategy-level arbitrage capital and then discuss the evolution of our capital measures over time.

\subsection{Short interest for extreme growth and loser stocks}

We start by testing the key premise underlying our methodology for measuring arbitrage capital: short interest should be high for stocks that a quantitative equity strategy recommends shorting. To do so, we run regressions that enable us to trace out the "event-time" path of short interest ratios for stocks falling into the lowest $B / M$ decile. Forecasting short interest is not our goal here. Rather, we simply want to understand the dynamics of short interest for the (selected) group of stocks that eventually fell into the extreme growth decile. We similarly trace out the event-time path of short interest for momentum losers.

The event-time paths are plotted in Figure 3 (the figure caption provides a detailed explanation of our methodology). Over our 1988-2011 sample, Figure 3 shows that entering the lowest $B / M$ decile raised short interest by 53 bps, whereas entering the lowest momentum decile raised short interest by 73 bps. The average short interest ratio in our sample is 226 bps, so these magnitudes are highly economically significant. Thus, Figure 3 confirms the key premise 
underlying our approach. ${ }^{19}$ We also estimate these specifications separately for the 1988-1999 and 2000-2011 subperiods. The impulse to short interest associated with becoming an extreme growth stock or momentum loser was clearly far larger in the later 2000-2011 subperiod than it had been in the 1988-1999 period.

\subsection{Measuring strategy-level capital using short interest}

Having confirmed the key premise underlying our measurement strategy, that is, that short interest is high for stocks that quantitative strategies recommend shorting, we now describe our empirical methodology in greater detail.

As we have shown in Section 1, a cross-sectional regression of short interest on a particular anomaly strategy signal is informative about the amount of capital devoted to that strategy. Notably, because our goal is to measure the amount of arbitrage capital devoted to a particular strategy (i.e., to detect strategy-level "crowding”, the reason a particular stock is being shorted matters for our purposes. For instance, a momentum trader who is worried that momentum strategies are becoming crowded does not simply want to know the level of short interest in a given loser stock; she also wants to know how many other momentum traders are shorting the loser stock. This information would help the momentum trader assess (1) whether her momentum signal is already impounded in the stock's price (i.e., assess the expected alpha of shorting the stock) and (2) the friction-related risks of shorting the stock, which likely stem from the common component of arbitrage frictions faced by other short sellers (see, e.g., Greenwood and Thesmar (2011)). In other words, we would like to isolate the marginal contribution of individual arbitrage strategies to stock-level short interest over and above other known determinants. To control for other known determinants of short interest, we favor an approach based on multivariate cross-sectional regressions over univariate alternatives (e.g., averaging short interest by $B / M$ deciles) because multivariate regressions allow us to better understand why stocks are being shorted.

Our methodology assumes that we know which stocks followers of a particular strategy would short. Clearly, quantitative investors use more sophisticated expected return models than

\footnotetext{
${ }^{19}$ Figure 3 shows that the increase in short interest for growth stocks is concentrated in the quarter at which they enter the lowest $B / M$ decile, whereas the increase in short interest for twelve-month momentum losers is more gradual. Presumably, this is because some arbitrageurs play shorter horizon (e.g., based on past six-month returns) momentum strategies.
} 
those implicit in the simple cross-sectional sorts used in this paper. Although our sorts will not perfectly capture the value or momentum portfolios generated by state-of-the-art quantitative investing techniques, our approach is a reasonable first approximation. Furthermore, Figure 3 confirms that arbitrageurs do respond to the information contained in our sorts.

We adopt a relatively nonparametric specification for our cross-sectional regressions. For each cross-section $t$, we regress stock $i$ 's short interest ratio on a full set of size, book-to-market, and momentum decile dummies

$$
S R_{i t}=\alpha_{t}+\mathbf{\kappa}_{t}^{B / M} \cdot \mathbf{1}_{i t}^{B / M}+\mathbf{\kappa}_{t}^{M O M} \cdot \mathbf{1}_{i t}^{M O M}+\mathbf{\kappa}_{t}^{S I Z E} \cdot \mathbf{1}_{i t}^{S I Z E}+\boldsymbol{\beta}_{t}^{\prime} \mathbf{x}_{i t}+\varepsilon_{i t} .
$$

The omitted dummy variable is always for decile 5 . The regression includes a full set of size $\left(\mathbf{1}_{i t}^{\text {SIZE }}\right)$ and momentum ( $\mathbf{1}_{i t}^{\text {MOM }}$ ) decile dummies as well as a vector $\left(\mathbf{x}_{i t}\right)$ of additional controls that have previously been shown to be important determinants of short interest: institutional ownership, threemonth turnover, trailing twelve-month return volatility, dummies for the exchange on which a stock trades, and a dummy that indicates whether a firm has convertible securities outstanding.

The coefficient on the dummy for the lowest momentum decile, $\kappa_{t}^{\text {MOM(1)}}$, reflects the increase in short interest at time $t$ associated with being an extreme loser relative to the omitted

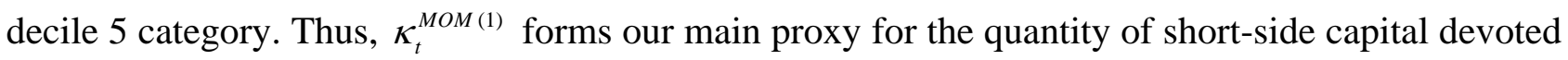
to momentum strategies at time $t^{20,21}$ As discussed above, our proxy is the strength of the crosssectional relationship between short interest and the momentum signal, not simply the total quantity of short interest in stocks in the lowest momentum decile.

Because we are primarily interested in low- and medium-frequency variation in strategy capital, we would like to reduce the measurement error associated with our monthly cross-sectional estimates. To do so, we use coefficients estimated from annual and quarterly panel regressions. Specifically, we stack all firm-month observations for a given year (or quarter) in a panel and

\footnotetext{
${ }^{20}$ The coefficients for other deciles are also potentially informative. For instance, if capital is flowing into momentum, we might see reductions in short interest for winners. In the Internet Appendix, we experiment with other capital, such as the spread in short interest between extreme losers and winners. These alternate measures lead to similar conclusions.

${ }^{21}$ Our baseline methodology uses equal-weighted regressions, so we are effectively measuring arbitrage capital in the average stock. To the extent that quantitative equity investors tend to implement their strategies primarily in small- and mid-cap stocks, our approach will be more informative than one that uses value-weighted regressions.
} 
estimate a single pooled regression that includes monthly fixed effects. However, all of our results are qualitatively unchanged if we simply use monthly cross-sections.

We have examined a number of other equity anomaly strategies in addition to value and price-momentum, including accruals, post-earnings-announcement-drift or “PEADs”, and net stock issuance. Many of the patterns we describe below for value and price-momentum also hold for these other anomalies. We provide a brief overview of these results in Section 4 and provide further results for these strategies in the Internet Appendix. In the Internet Appendix, we also plot and discuss the cross-sectional $R^{2}$, the number of observations, and the coefficients on the additional control variables from our baseline regression specification in Equation (5).

\subsection{Validating the measure of strategy-level arbitrage capital}

Before turning to our main analysis, we provide evidence that our measure is indeed proxying for arbitrage capital. Figure 4 plots the coefficients for the lowest $B / M$ and momentum deciles along with the associated 95\% confidence intervals from 1988-2011. These coefficients, which are also listed in Table A.1 of the Internet Appendix along with the associated standard errors, show the boost in short interest (in percentage points) for stocks in the lowest $B / M$ and momentum deciles relative to stocks in decile 5 . Figure 4 also plots estimates based on three-month rolling windows as discussed above. These plots highlight several higher frequency movements in arbitrage capital. For instance, there is a clear decline in the shorting of growth stocks during the tech bust from 2000 to 2001. Short interest for extreme loser stocks reached an all-time peak in June 2007, just before the quant meltdown of August 2007. In the analysis below, we will interpret these high-frequency movements in our measures as changes in arbitrage capital. To help validate this interpretation, we now conduct several tests.

3.3.1 Comparison with other capital measures. We first compare our measures to external measures of hedge fund capital. The correlation between our measures and the assets under management (AUM) of Equity Market Neutral hedge funds reported by Thompson Lipper is 0.83 for $B / M$ and 0.60 for momentum. ${ }^{22}$ This suggests that our measures capture the broad trends in

\footnotetext{
${ }^{22}$ The AUM numbers are from the Lipper TASS Hedge Fund Asset Flows report published by Thomson Reuters.
} 
aggregate capital for quantitative equity hedge funds. ${ }^{23}$

3.3.2 Additional stock-level controls. Despite this correlation with measures of aggregate hedge fund AUM, one might be concerned that the higher-frequency movements in our capital measures largely reflect changes in the liquidity or "shortability" of stocks in the lowest $B / M$ or momentum deciles, rather than genuine variation in the amount of capital using these strategies. Of course, we control for various characteristics associated with shortability in regression (8), but these controls may be imperfect. However, we obtain virtually identical results if we include additional proxies for shortability, including the Amihud (2002) illiquidity measure, analyst coverage (i.e., the number of analysts reporting EPS estimates in I/B/E/S), a dummy for stocks in the S\&P 500, and option open interest from OptionMetrics. We can further address this concern by constructing capital measures based on our full 1988 to 2011 panel data set. Specifically, we run panel regressions that allow for time-varying slopes on our decile dummies and include stock-level fixed effects. The resulting measures should not be driven by shifts in shortability of extreme growth or loser stocks_-assuming the omitted shortability factor is a fixed stock-specific attribute. Reassuringly, the correlation between the resulting measures and our baseline measures is 0.99 for value and 0.98 for momentum. $^{24}$

3.3.3 Demand versus supply shifts. Finally, one might be concerned that variation in our capital measures is driven solely by an expansion of share lending supply: perhaps arbitrageur demand to short growth and loser stocks has always been high and has simply been revealed in short interest quantities as supply constraints have eased. In this subsection, we argue that changes in shorting demand have played an important, although not exclusive role, in driving increased shorting of anomaly stocks. However, many of the equilibrium asset pricing implications for anomaly strategies derived in Section 1 notably rely only on an increase in the total amount of arbitrage capital, regardless of whether it stems from an increase in short-seller demand or in share-lending supply. Thus, the analysis relating capital to returns in the Section 4 of the paper does not hinge on a

\footnotetext{
23 This does not simply reflect a common time trend: regressing our strategy capital measures on the Lipper capital measure and a time trend yields a positive significant coefficient ( $t=2.16$ for $B / M$ and $t=3.49$ for momentum).

${ }^{24}$ We can also address this concern by estimating (1) using only what Savor and Gamboa-Cavazos (2011) call

“shortable” stocks — those with a price over \$5 and in NYSE size deciles 2-10—which yield very similar results.
} 
specific decomposition of shifts in short interest into demand-driven versus supply-driven shifts.

However, there are good reasons to think that some of the variation in our capital measures is driven by demand shifts. First, note that a general outward shift in share lending supply for all stocks would be captured by a changing constant in our cross-sectional regressions (i.e., $\alpha_{t}$ in Equation (5)) and cannot account for our findings. In other words, the time trends in cross-sectional regression coefficients in Figure 4 are analogous to significant difference-in-differences and cannot be explained by a generalized expansion in lending supply (or a generalized increase in shorting demand). Instead, a supply-side explanation would need to argue that there has been a differential expansion in the effective lending supply for loser stocks and growth stocks relative to other stocks.

Second, we provide additional evidence that suggests that our measures are picking up changes in shorting demand, not changes in supply, by using institutional ownership, $I O_{i t}$, as a proxy for the lendable supply of stock $i$ at time $t .^{25}$ Figure 5 depicts a stylized view of the equity lending market. D’Avolio (2002) argues that shorting supply curves are kinked, highly elastic for $S R_{i t}<c_{i t} \cdot I O_{i t}$, and inelastic beyond that kink. Here, $c_{i t} \in[0,1]$ represents the fraction of institutional owners with active share lending programs. If $S R_{i t}<c_{i t} \cdot I O_{i t}$, shorting supply is highly elastic, the stock is considered "general collateral," and the lending fee typically will be quite small. If $S R_{i t}>C_{i t} \cdot I O_{i t}$ (i.e., the supply constraint begins to bind), the stock is said to be on "special" and short-sellers wishing to borrow shares will have to pay a larger fee. The figure suggests that short interest in stocks with high institutional ownership is unlikely to be affected by loosening supply constraints. It is likely that $S R_{i t}<C_{i t} \cdot I O_{i t}$ for short stocks, so outward shifts in the kink or changes in the cost of shorting constrained stocks will not affect equilibrium short interest quantities. ${ }^{26,27}$

\footnotetext{
${ }^{25}$ Because data on the relevant prices are only available in recent years, we cannot separate supply-and-demand shifts using the approach of Cohen, Diether, and Malloy (2007). Specifically, data on share lending fees and amounts are only available from Markit Securities Finance beginning in 2003. Because we analyze the evolution of quantitative equity arbitrage since 1988 and since 1973 for NYSE and AMEX stocks, we cannot use this data to rule out supply-based explanations for the long-term trends in our measures. Geczy, Musto, and Reed (2002) also use data on share lending fees to argue that supply constraints cannot account for the profitability of equity anomaly strategies.

${ }^{26}$ Using data on short interest and lending fees, Kolasinski, Reed, and Ringgenberg (2012) exploit plausibly exogenous shocks to shorting demand to estimate lending supply curves. Their findings also suggest that lending supply curves are flat unless short interest represents a substantial fraction of lendable supply $\left(c_{i t} \cdot I O_{i t}\right.$ in the above notation).

${ }^{27}$ However, the fee for shorting unconstrained stocks may have dropped (i.e., the horizontal segment of the supply curve may have shifted). Shifts in the general collateral lending fee will affect equilibrium short interest for both
} 
This analysis leads to two important predictions of a supply-based explanation. First, we can directly examine time variation in the lending supply of decile 1 stocks by running regressions like (5), where the dependent variable is institutional ownership. If our findings largely reflect differential shifts in lending supply, the coefficients for growth and loser stocks from these $I O$ regressions should look similar to the coefficients from the short interest regressions in Figure 4. In practice, the resulting time series of coefficients have low correlations $(0.27$ for $B / M$ and 0.28 for momentum) with our capital measures, suggesting that shifts in the supply of decile 1 stocks are unlikely to drive our results. ${ }^{28}$

Second, if shorting demand has been relatively constant, we should not see significant time trends once we condition on institutional ownership. Instead, we should simply find that the time series for unconstrained stocks lies above that for constrained stocks. Under a pure supply shift hypothesis, our aggregate trend simply reflects a changing mix of these two flat lines. By contrast, if there have been important shifts in shorting demand, we would expect to see trends for both the unconstrained and constrained stocks. A time trend for the high $I O$ stocks would be especially suggestive of an outward shift in shorting demand, that is, of an increase in arbitrage capital.

Because shifts in lending supply are likely to be most important for small stocks, we focus on small stocks (size deciles 1 and 2) and use a fixed ownership cutoff of 30\%, so stocks with $I O_{i t}$ $<30 \%$ are considered to have low institutional ownership. This $30 \%$ cutoff is close to the median institutional ownership across all observations in our sample of 33.5\%. For each cross-section, we run our baseline specification (5) separately for small stocks with low IO and small stocks with high IO. We use NYSE quintiles as opposed to deciles for book-to-market and momentum to ensure a sufficient number of observations to identify each coefficient.

Figure 6 plots the time series of coefficients for the lowest $B / M$ and momentum quintiles for small stocks, broken out by high and low institutional ownership. These coefficients show the boost

unconstrained stocks and are thus harder to disentangle from demand shifts. However, general collateral lending fees have been quite stable over time. Furthermore, such shifts will only have large effects on equilibrium short interest if shorting demand curves are extremely price elastic, which seems unlikely.

${ }^{28}$ The fraction of institutions who lend their shares ( $c_{i t}$ in the above notation) may have risen differentially for growth and loser stocks. Unfortunately, there is little we can do to directly rule out this story. However, given that most institutional investors do not exhibit strong value or momentum tilts (Lewellen 2011) and typically make a large fraction of their holdings available once they establish share lending programs, this possibility seems highly unlikely. 
in short interest relative to stocks of similar size and similar institutional ownership. Shorting of small growth stocks with low $I O$ has increased, consistent with the idea that share supply constraints have eased for this group. Furthermore, there is essentially no increase in short interest for small momentum loser stocks with low institutional ownership. ${ }^{29}$ However, the results for smallcaps with high institutional ownership are the key to our argument. Here, we find large increases in short interest for both growth and loser stocks. Because it is unlikely that shorting of these high-IO stocks was ever constrained by share lending supply, Figure 6 suggests that there has been a large increase in shorting demand for growth and loser stocks.

In summary, the evidence suggests that differential shifts in shorting demand have played an important, though perhaps not exclusive, role in shaping the trends described above. In other words, the evidence suggests we are justified in interpreting the coefficients $\kappa_{t}^{B M(1)}$ and $\kappa_{t}^{M O M(1)}$ from Equation (5) as measures of the amount of capital devoted to value and momentum, respectively.

\subsection{Trends in value and momentum capital from 1988-2011}

Having validated our measure of strategy-level capital, we now return to the time series of estimated capital intensities in Figure 4 that are estimated from annual cross-sectional regressions. A key advantage of our methodology over measures of hedge fund capital available from vendors like Lipper and HFR is that it allows us to assess the amount of capital devoted to individual quantitative equity strategies (i.e., value versus momentum). We first consider the relative magnitudes of our capital measures. On average, over our 1988-2011 sample, $\hat{\kappa}_{t}^{B / M(1)}=107$ bps and $\hat{\kappa}_{t}^{\text {MOM(1) }}=45$ bps. We also find that $\hat{\kappa}_{t}^{B / M(1)}$ is greater than $\hat{\kappa}_{t}^{\text {MOM(1) }}$ in each year. This suggests that more arbitrage capital has been allocated to value strategies than to momentum strategies. Value strategies have a longer history among practitioners, dating back to Graham and Dodd (1934), than momentum strategies and are used by a variety of sophisticated investors other than quantitative hedge funds. Thus, finding that more arbitrage capital has been dedicated to value strategies seems natural.

Next, we consider the time variation in our capital measures. Because we have already

${ }^{29}$ One explanation is that the high turnover of momentum makes the strategy unattractive in small stocks with low IO. 
addressed concerns that variation in our measures is driven by share lending supply, a positive time trend would be evidence in favor of Prediction 1 from Section 1, that is, that the arbitrage capital dedicated to value and momentum has increased over time. Consistent with anecdotal evidence, Figure 4 suggests that large amounts of arbitrage capital have flowed into value and momentum strategies, particularly since 2001. Specifically, Figure 4 shows that there has been a steady increase in short interest for extreme growth and loser stocks. Regressing $\hat{\kappa}_{t}^{B / M(1)}$ on a time trend reveals a trend of +7.2 bps per annum $(t=10.5)$. Although the trend for $\hat{\kappa}_{t}^{M O M(1)}$ is smaller at +3.0 bps per annum $(t=5.3)$, both $\hat{\kappa}_{t}^{B / M(1)}$ and $\hat{\kappa}_{t}^{M O M(1)}$ have grown more than fivefold over the past 24 years.

\subsection{Trends in capital for small and large stocks}

Do these results vary with stock size? Figure 2 shows that the increase in aggregate short interest has been largest in NYSE size deciles 2-5. The growth of arbitrage capital has also possibly been the largest in small and mid-cap stocks.

To understand these size interactions, we break each of the $B / M$ decile into three categories: small stocks (NYSE size deciles 1 and 2), medium stocks (deciles 3-5), and big stocks (deciles 610). In Figure 7, we plot our measure of value capital for each category. These coefficients represent the boost in $S R$ associated with being an extreme growth stock relative to being a valueneutral (decile 5) stock in the same size category.

As expected, Figure 7 reveals a steady increase in short interest for small- and medium-cap growth stocks. A regression of our measure of value capital for small stocks, $\hat{\kappa}_{t}^{B / M(1), S M A L L}$, on time yields a trend of +10.5 bps per annum $(t$-statistic $=7.2)$. The trend for medium stocks is similar at +9.9 bps per annum $(t=4.2)$. Large growth stocks also evince an upward trend over time, interrupted by a decline during the tech bubble, and rebounding in recent years.

We find similar patterns for extreme momentum losers. Specifically, we see increased shorting of small losers since the mid-1990s. The trend for our measure of momentum capital among small stocks, $\hat{\kappa}_{t}^{M O M(1), S M A L L}$, is +6.0 bps per annum $(t=6.3)$. There is also a small upward trend in mid-cap loser stocks, but not large-caps. Large-cap loser stocks were actively shorted in mid-1990s, but this has not been the case since 2000. Overall, we find similar trends for stocks of all sizes, though the upward trends in arbitrage capital are strongest for small and mid-cap stocks. 
However, our results are not driven by micro-cap stocks: we obtain very similar time-series measures of arbitrage capital if we restrict attention to stocks in size deciles 2-10.

\subsection{Arbitrage capital on the AMEX and NYSE, 1973-2011}

For AMEX and NYSE stocks, we can investigate patterns of short interest dating all the way back to 1973. In Figure 8 we estimate Equation (5) each year from 1973 to 2011, now restricting attention to AMEX and NYSE stocks only. Figure 8 suggests that at least some short sellers were aware of and traded on value and momentum signals prior to the explosion of academic interest in these strategies in the early 1990s. This is perhaps not surprising if one recalls that many of the early academic studies that explored anomalies in the cross-section of expected stock returns were motivated by investor claims that these strategies generated abnormal excess returns. ${ }^{30}$

To summarize, we provide strong evidence that the amount of arbitrage capital devoted to value and momentum has grown over time, confirming Prediction 1 developed above.

\section{Arbitrage Capital and Asset Prices}

We now turn to testing the asset-pricing predictions developed in Section 1. The low-frequency growth of arbitrage capital suggests that the excess risk-adjusted returns to anomaly strategies may be competed away over time. However, the large theoretical literature on limits of arbitrage suggests that these abnormal returns may persist, even in the long run. To explore these competing intuitions, we turn to the relationships between our measures of arbitrage capital and strategy returns. As discussed in Section 1, we first examine the effect of the level of capital on returns. We then examine the relationship between capital flows and strategy returns and interpret the evidence in light of theories of limited arbitrage.

We use $\kappa_{t}^{s}$ to denote the coefficient on the decile 1 dummy for strategy $s$ from the crosssectional short interest regression at time $t$. We interpret $\kappa_{t}^{s}$ as the level of capital in strategy $s$ at time $t$. We work with quarterly data from 1988Q3 to 2011Q4, so $\kappa_{t}^{s}$ is estimated by running

\footnotetext{
${ }^{30}$ In part, Jegadeesh and Titman (1993) were motivated to condition on past twelve-month returns by the perception that a number of mutual funds appeared to use "relative strength trading rules.” The academic literature on value-based strategies began even earlier, with contributions from Ball (1978), Stattman (1980), Basu (1983), and Rosenberg, Reid, and Lanstein (1985). Arguably, however, academic interest in value signals only exploded following the publication of Fama and French (1992), Fama and French (1993), and Lakoniskok, Shleifer, and Vishny (1994).
} 
regression (5), where all monthly observations in a given quarter are pooled together in a single panel. Using coefficients from monthly cross-sectional regressions introduces greater noise into the $\kappa_{t}^{s}$ measures, but yields similar results. We use quarterly changes in these coefficients, $\Delta \kappa_{t}^{s}=\kappa_{t}^{s}-\kappa_{t-1}^{s}$, to proxy for strategy-level capital flows in quarter $t$. Our $\kappa_{t}^{s}$ and $\Delta \kappa_{t}^{s}$ measures have units of basis points of short interest (one basis point equals $0.01 \%$ ). These are natural economic units as they inherit the units of short interest, expressing the amount of arbitrage capital allocated to a given equity anomaly strategy as a fraction of the total market value of the stocks in that strategy's portfolio.

We use the HML and UMD factor returns available from Kenneth French's Web site to proxy for the returns to value and momentum strategies, respectively. ${ }^{31}$ We cumulate the monthly returns to form quarterly and annual factor returns. We also compute one-quarter rolling factor volatilities, $\sigma_{t}^{s}$, as the standard deviation of daily factor returns for strategy $s$ during quarter $t$. The quarterly and annual returns are in percentages, and our factor volatility measures are in annualized percentages. To proxy for the returns to hedge funds more generally, we use the return index for long/short "Equity Hedge” hedge funds available from Hedge Fund Research (HFR).

We present the results for three different samples: (1) the 1988Q3-2011Q4 sample for all CRSP stocks, (2) the 1988Q3-2007Q4 subsample (i.e., excluding the recent financial crisis) for all CRSP stocks, and (3) 1973Q1-2011Q4 for NYSE and AMEX stocks only. We present results for the subsample excluding the crisis because, whereas the crisis was a period when arbitrage constraints may have bound tightly, the short-sales bans and withdrawal of share supply due to concerns about the reinvestment portfolios of securities lenders led to wild fluctuations in short interest (Boehmer, Jones, and Zhang 2012). Thus, we present results for the precrisis period to understand how these outlying observations affect the results. We present the 1973-2011 sample results because they give us a valuable window into the growth of arbitrage capital over a nearly forty-year sample. However, short interest is only available for NYSE and AMEX stocks over this

\footnotetext{
${ }^{31}$ We use $H M L$ and $U M D$, which are essentially value-weighted strategy returns, for comparability with the previous literature. Given that the growth of our capital measures is strongest in small- and mid-cap stocks, our measures may be more highly correlated with equal-weighted returns. In Table A.2 of the Internet Appendix, we show that we obtain largely similar and perhaps even somewhat stronger results using equal-weighted strategy returns.
} 
longer sample period, somewhat limiting the generality of this analysis.

\subsection{Evolution of arbitrage: Long-term trends}

Following the conceptual framework developed in Section 1, we first examine the effect of the level of capital on the level of anomaly returns. We then examine whether higher levels of arbitrage capital have led to a more rapid decay of the profitability of anomaly signals.

4.1.1 Effects of the level of capital on future returns. We first examine Prediction 2, asking whether the growth of arbitrage capital has been associated with a decline in the returns to these strategies. In Table 2, we regress strategy returns over the following four quarters on the initial level of strategy capital

$$
r_{t \rightarrow t+4}^{s}=\mu+\beta \cdot \kappa_{t}^{s}+\varepsilon_{t \rightarrow t+4}^{s}
$$

Because of the overlapping returns, the $t$-statistics here are computed using Newey-West (1987) standard errors, allowing for six quarterly lags. The coefficients in Table 2 are generally negative, but our small sample limits our statistical power to detect changes in mean returns. Only when we use our longer 1973-2011 sample of NYSE and AMEX stocks do we find statistically significant evidence that higher levels of capital are associated with lower future returns. Specifically, the results in Column (5) suggest that a ten-basis-point increase in value-strategy arbitrage capital is associated with a $1.23 \%$ decline in the expected annual returns to a value strategy. ${ }^{32}$

Table 3 presents another effort to enhance the statistical power of these tests. Specifically, we expand the set of anomaly strategies we examine to include value, momentum, net share issuance (Fama and French 2008; Pontiff and Woodgate 2008), accruals (Sloan 1996), and postearnings-announcement drift (Bernard and Thomas 1989, 1990). We pool our arbitrage capital measures and returns into a strategy-level panel dataset consisting of these five anomaly strategies and regress strategy returns over the following four quarters onto the initial level of strategy capital as in Equation (6). The construction of the long/short returns for strategies other than value and momentum follows the Fama and French (1993) procedure for constructing HML. ${ }^{33}$

\footnotetext{
${ }^{32}$ Untabulated results show that our finding in Column (5) is robust to controlling for the level of the value spread as in Cohen, Polk, and Vuolteenaho (2003), past HML returns, contemporaneous MKTRF realizations, and a time trend.

${ }^{33}$ Firms are independently sorted into low, neutral, and high groups of characteristic $s$, using $30 \%$ and $70 \%$ NYSE breakpoints, and into small or big groups based on the NYSE size median. We compute value-weighted returns within
} 
These results are shown in Columns (1) and (2) of Panel A, and we now see stronger statistical evidence that higher strategy capital is associated with lower future strategy returns. The panel estimates suggests that a ten-basis-point increase in strategy capital is associated with a $0.40 \%$ decline in the expected annual strategy returns. Columns (3) and (4) repeat this exercise, allowing for strategy-level fixed effects, so we now estimate

$$
r_{t \rightarrow t+4}^{s}=\mu_{s}+\beta \cdot \kappa_{t}^{s}+\varepsilon_{t \rightarrow t+4}^{s} \text {. }
$$

Adding strategy fixed effects ensures that $\beta$ is identified solely from within-strategy, time-series variation in capital and returns. (By contrast, the estimates without fixed effects are also identified using between-strategy, cross-sectional variation.) Adding strategy fixed effects, slightly reduces the magnitude of the estimated effect and reduces statistical power. However, the estimated effect remains negative and significant even with the addition of strategy fixed effects.

In summary, the results in Table 2 and Table 3, Panel A, suggest that increasing arbitrage capital has been associated with declining strategy returns, consistent with Prediction 2. Thus, our results are related to the existing literature, including Asquith, Pathak, and Ritter (2005), BenDavid, Drake, and Roulstone (forthcoming), and Cohen, Diether, and Malloy (2007), among many others, showing that high short interest negatively forecasts stock returns in the cross-section. The existing literature shows that stocks with relatively high short interest do worse than do stocks with relatively low short interest. Our results speak to the magnitude of that relative outperformance over time. We show that as more arbitrageurs exploit a particular anomaly signal, they arbitrage it away, making the relationship weaker. In other words, one would still expect high short interest to be associated with lower returns in each individual cross-section, but perhaps less strongly than in the past.

\subsubsection{The decay of anomaly profits following portfolio formation. We now turn to Prediction} 3, and ask whether the growth of arbitrage capital has led the profitability of anomaly signals to decay more rapidly following portfolio formation. To do so, we construct portfolios at the end of

these six size-by- $k$ buckets. The long-short return for characteristic $s$ is $r^{s}=1 / 2\left(r_{B H}-r_{B L}\right)+1 / 2\left(r_{S H}-r_{S L}\right)$, where, for example, $r_{B H}$ is the value-weighted return on big, high-s stocks. The long-short portfolios based on accruals and net share issuance are reformed each quarter. The long-short PEADs portfolio, formed by sorting on standardized unexpected earnings $\left(S U E_{i t}\right)$, is rebalanced each month restricting attention to firms that have announced earnings within the past forty business days. 
each quarter for each strategy $s$ following the procedure described above. We then compute a measure of the ex-post-realized persistence of the profitability of this initial signal. For each quarterly portfolio formation date, we count the amount of time that elapses (in years) before the postformation cumulative returns to holding this portfolio turn negative, $Z_{t \rightarrow t+12}^{s}$. Technically, we wait one month (twenty trading days) following portfolio formation before asking how long cumulative returns take to turn negative. If the cumulative returns for a given portfolio do not turn negative within three years, we top code the variable at three years.

The results are shown in Table 4. The results in Columns (5) and (6) suggest that, over the 1973-2011 period, increases in value capital have been associated with a more rapid decay of the profitability of value signals. This result is robust to controlling for a simple time trend, suggesting that the growth of arbitrage capital per se may have played some role. There is some evidence that the growth momentum capital has been associated with a more rapid decay of momentum signals following portfolio formation. However, we find strong evidence of a time trend in the rate of

momentum signal decay; for example, the trend coefficients in Columns (8) and (10) suggest that, on average, momentum signals decayed 0.82 to 0.96 years faster at the end of our sample than in the beginning of the sample.

Turning to the panel version of these regressions in Panel B of Table 3, we find some evidence that anomaly signals have decayed more rapidly as strategy-level arbitrage capital has risen. However, these results are less robust to the inclusion of a simple time trend as a control. Indeed, Panel B of Table 3 strongly suggests that all anomaly signals now tend to decay more rapidly following portfolio formation than they did twenty-five years ago. Thus, we have a limited ability to assess whether increases in strategy capital, itself trending up over time, have played a significant role in determining the persistence of anomaly profits or whether the underlying factors generating these anomalies (e.g., investor under-reaction to new information) has trended down over time. In practice, both increasing arbitrage capital and the increasing availability of timely information to investors have likely played a role in reducing anomaly returns.

\subsection{Limits of arbitrage: Short-term feedback between strategy returns and capital flows}

Having found evidence that the growth of arbitrage capital has been associated with lower anomaly 
returns, we now ask whether the quantitative equity arbitrage appears to suffer from meaningful limits to arbitrage. As discussed in Section 1, if we find evidence of significant limits to arbitrage, the excess returns associated with equity anomaly strategies may not be completely eliminated, even in the long run.

4.2.1 Effects of past strategy returns on capital flows. We start with Prediction 4 and ask whether there is evidence of a performance-flow relationship at the strategy level. A key ingredient in the literature on limits of arbitrage is the existence of a performance-flow relationship (Shleifer and Vishny 1997), which one would expect in the absence of a fundamental anchor (Stein 2009). A handful of papers have also found evidence of a positive performance-flow relationship at the level of the aggregate mutual fund or hedge fund industry. ${ }^{34}$

Why might we expect a performance-flow relationship to exist at the strategy level? First, fund managers may themselves chase performance across strategies. Second, a fund-level performance-flow relationship may lead to a strategy-level performance-flow relationship if investors chase performance across funds that mix strategies in different proportions. Unfortunately, we will not be able to disentangle these two competing explanations because our measures simply reflect the equilibrium amount of strategy-level arbitrage capital. However, from an asset pricing perspective, these two explanations have similar implications - arbitrage capital devoted to a given strategy declines following poor returns.

In Table 5, we regress capital flows in quarter $t$ on strategy returns in quarter $t-1$ :

$$
\Delta \kappa_{t}^{s}=\alpha+\beta \cdot r_{t-1}^{s}+\varepsilon_{t}^{s}
$$

The $t$-statistics are computed using heteroscedasticity-robust standard errors. There is little evidence of a quarterly performance-flow relationship for value strategies. In fact, the point estimate for $\beta$ is slightly negative, consistent with the idea that value has a "fundamental anchor." Specifically, as argued by Cohen, Polk, and Vuolteenaho (2003), the "value spread", that is, the difference in average book-to-market between value and growth stocks, is a natural indicator of the conditional expected returns to value strategies. Thus, if investors allocate capital across strategies in a forward-

\footnotetext{
${ }^{34}$ Goetzmann and Massa (2003) find evidence of daily performance-flow relationship using U.S. index funds. Specifically, outflows increase following down-market days. Wang and Zheng (2008) find a positive relation between quarterly aggregate hedge fund flows and past aggregate hedge fund returns using Lipper TASS data.
} 
looking way, one would not expect to find a strong positive performance-flow relationship for value because the value spread (and hence expected future value returns) rises following poor value returns.

By contrast, we find a reliably positive performance-flow relationship for momentum, which does not have a fundamental anchor, in the pre-2008 period. The magnitudes here seem reasonable. The estimates indicate that a 10\% quarterly momentum return generates capital flows of $6.7 \mathrm{bps}$, a meaningful inflow given that the mean and standard deviation of quarterly momentum flows are 1.2 and 31.5 bps, respectively.

Turning to Panel C of Table 3, we examine the performance-flow relationship in our panel of five quantitative equity strategies. Interestingly, there is some evidence that the high returns are followed by capital outflows. This is consistent with the idea that three out of the five strategies studied (value, net stock issuance, and accruals) have fundamental anchors. Overall, the evidence in this section finds a positive performance-flow relationship only for momentum strategies.

4.2.2 Contagion and spillovers across strategies. Turning next to Prediction 5, we investigate how contagion or deleveraging spillovers across strategies may limit arbitrage. Specifically, we examine the effects of the returns on other strategies on the arbitrage capital in a given strategy. Suppose there are two strategies, $A$ and $B$, and that there is an initial adverse shock to the returns of strategy $A$. In the regression

$$
\Delta \kappa_{t}^{B}=\alpha+\gamma \cdot r_{t-1}^{A}+\beta \cdot r_{t-1}^{B}+\varepsilon_{t}^{B},
$$

the coefficient $\gamma$ captures the effects of strategy- $A$ returns on strategy- $B$ capital flows. Limits-ofarbitrage or deleveraging stories would suggest that $\gamma$ will be large and positive when many arbitrageurs play both strategies $A$ and $B$. By contrast, if strategies $A$ and $B$ are used by entirely distinct sets of arbitrageurs, $\gamma$ would be close to zero.

In Table 6 we regress $\Delta \kappa_{t}^{M O M}$ on the lagged momentum strategy return (i.e., $U M D_{t-1}$ ), the lagged market return (i.e., $M K T R F_{t-1}$ ), and the lagged return on HFR indexes, which track the performance of Equity Hedge (long/short) hedge funds ${ }^{35}$ Hedge fund returns, rather than individual

\footnotetext{
${ }^{35}$ The HFR indices are only available starting in 1990, so we lose several observations at the beginning of the sample.
} 
returns to other strategies, are likely to be the most powerful indicators of contagion because they "correctly" weight returns to other strategies. The table shows strong evidence that momentum capital flows, $\Delta \kappa_{t}^{M O M}$, respond to hedge fund returns in addition to $U M D_{t-1} \cdot{ }^{36}$ For instance, Column (4) shows that, holding $M K T R F_{t-1}$ and $U M D_{t-1}$ fixed, a one-percentage-point increase in the lagged return on HFR's Equity Hedge index $\left(E H E D G E_{t-1}\right)$ is associated with a 2.6 bps increase in short interest for extreme losers. Thus, a one-standard-deviation increase in $E H E D G E_{t-1}$ (the standard deviation of monthly EHEDGE $E_{t-1}$ is $5.7 \%$ ) is associated with a 15.2 bps increase in $\kappa_{t}^{\mathrm{MOM}}$, a large increase given that the standard deviation of $\Delta \kappa_{t}^{M O M}$ is $31.5 \mathrm{bps}$. In untabulated results, we find that the effect of $E H E D G E_{t-1}$ is nearly three times larger for negative returns than for positive returns.

In line with Prediction 5, these results are consistent with the existence of cross-strategy spillovers. When other long/short equity strategies do poorly, our results suggest that arbitrageurs liquidate momentum positions. Although we cannot definitively explain this empirical pattern, one explanation is that arbitrageurs use the proceeds from these liquidations to meet margin requirements or capital redemptions.

\subsubsection{Effects of strategy volatility and funding constraints on capital flows. We next test}

Prediction 6, asking whether there is evidence that binding funding constraints may sometimes limit quantitative equity arbitrage. Even in the absence of a performance-flow relationship, stemming from the (equity) capital contributions and withdrawals of "end investors," arbitrage may be limited if the leverage supplied to arbitrageurs by other intermediaries is limited at certain times. Garleanu and Pedersen (2011) argue that arbitrageur leverage may be limited when past volatility is high, as this induces lenders to tighten margins (i.e., to raise "haircuts" on the collateralized loans they extend to arbitrageurs), whereas Frazzini and Pederesen (2011) argue that the Treasury Eurodollar (TED) spread is a good proxy for the tightness of margin constraints. Table 7 considers the effect of changes in strategy return volatility on strategy capital flows:

\footnotetext{
${ }^{36}$ We find little evidence that the returns on other factors help explain $\Delta \kappa_{t}^{B / M}$. One possibility is that there is a large group of arbitrageurs that only play value, which may contrast with momentum. These value investors may have longer horizons and use low leverage, so they are both willing and able to withstand wealth or contagion effects. Based on conversations with quantitative investors, there are reportedly few pure momentum arbitrageurs. Momentum is a highly volatile strategy, and so it is typically paired with other strategies to diversify away some of its idiosyncratic risk.
} 


$$
\Delta \kappa_{t}^{s}=\alpha+\psi \cdot \Delta \sigma_{t-1}^{s}+\tau \cdot \Delta \sigma_{t-1}^{M K T}+\lambda \cdot \Delta T E D_{t-1}+\varepsilon_{t}^{s} .
$$

There is evidence of the predicted negative relationship between changes in volatility and capital flows for value. Specifically, when we regress our value capital flow measure on lagged changes in one-quarter HML volatility, we obtain a negative and significant coefficient. What is the magnitude of the estimated effect? The coefficient of -2.239 in Column (1) implies that a 10\% spike in $H M L$ volatility is associated with a 22 bps decline in our value capital measure. The mean and standard deviation of our value capital flows are 2.2 bps and 21.5 bps, respectively, so this is an economically significant effect.

By contrast, there is no evidence of the hypothesized negative relationship for momentum. This may be because realized one-quarter volatility fluctuates more for momentum than for value. Changes in one-quarter momentum volatility have a standard deviation that is $60 \%$ higher than for changes in one-quarter value volatility.

When we examine the relationship between strategy capital and funding constraints, proxied by the Treasury Eurodollar (TED) spread, we find a strong negative relationship for momentum but little relationship for value.

Turning to Panel D of Table 3, we test whether increases in strategy volatility and tighter funding constraints reduce strategy-level arbitrage capital using our panel of five quantitative equity strategies. The effect of past strategy volatility is strongly negative and significant in these panel regressions. However, there is little evidence that the TED spread plays an important separate role. Overall, the results suggest that volatility limits strategy-level arbitrage capital, consistent with Prediction 6 in Section 1.

4.2.4 Arbitrage capital flows and future strategy returns. Finally, we examine Prediction 7 and ask whether the frictions limiting arbitrage lead arbitrageurs to mistime strategy returns. If arbitrageurs are unconstrained, then they should increase their strategy capital allocations when they anticipate high returns going forward. If, on the other hand, they are constrained by capital withdrawals or binding leverage constraints when expected returns are high, the relationship between capital allocations and future returns will be negative. In Table 8 we forecast strategy returns over the next four quarters using capital flows over the prior four quarters 


$$
r_{t \rightarrow t+4}^{s}=\mu+\varphi \cdot\left(\kappa_{t}^{s}-\kappa_{t-4}^{s}\right)+\varepsilon_{t \rightarrow t+4}^{s}
$$

Because of the overlapping returns, the $t$-statistics here are computed using Newey-West (1987) standard errors, allowing for six lags.

There is reliable evidence that recent capital flows negatively forecast future value returns. This result continues to hold even after controlling for the value spread $\left(V S_{t}\right.$ is the difference in average $B / M$ between value and growth stocks at time $t$ ), which positively forecasts $H M L$ returns (Cohen, Polk, and Vuolteenaho 2003). The result is also robust to controlling for the cumulative return over the prior four quarter, $r_{t-4 \rightarrow t}^{B / M}$, to capture the mean reversion in $H M L$ identified in Teo and Woo (2004). The effects in Table 8 are economically significant. Because the returns here are in percentage points and the coefficients are in basis points, the coefficient for $\kappa_{t}^{B / M}-\kappa_{t-4}^{B / M}$ in Column (1) implies that a $10 \mathrm{bp}$ increase in our capital measure forecasts that future annual $H M L$ returns will decline by $1.2 \%$.

Table 8 also examines the low-frequency relationship between returns and capital for momentum. As with value, regressing future $U M D$ returns on past capital flows, $\kappa_{t}^{M O M}-\kappa_{t-4}^{M O M}$, reveals evidence that capital flows negatively forecast momentum returns in the pre-2008 period. However, this result disappears during the financial crisis period, as arbitrageurs appear to have successfully exited momentum before they incurred low returns, possibly due to the partial short sales ban imposed for financial stocks in September 2008. ${ }^{37}$

Turning to Panel E of Table 3, we examine the evidence that capital flows forecast future returns using our broader panel of five quantitative equity strategies. In these panel regressions, strategy-level capital flows continue to negatively and significantly forecast strategy returns, consistent with theories of limited arbitrage.

An alternative explanation of these results is that arbitrageur perceptions of the profitability of an anomaly signal could vary over time, holding fixed the quantity of capital available to arbitrageurs. Specifically, our measure of capital is not short interest itself but is rather the crosssectional relationship between short interest and a given anomaly signal. Thus, our measure could

\footnotetext{
${ }^{37}$ As discussed in the Internet Appendix, short interest for extreme losers falls for both nonfinancial and financial stocks following September 2008. However, the decline for financials is far more pronounced than is that for nonfinancials.
} 
impound information not only on the quantity of arbitrage capital at a given time but also on how strong arbitrageurs perceive the anomaly signal to be at that moment, that is, the perceived strength of the cross-sectional relationship between the anomaly signal and future returns.

Although we cannot cleanly disentangle variation in the capital available to arbitrageurs and variation in arbitrageur expectations of strategy profitability, we believe that the most plausible explanation of our forecasting results appeals to time variation in arbitrage capital. Specifically, as arbitrageur capital rises, we would expect anomaly returns to decrease as short sellers increasingly arbitrage away potential mispricing. In contrast, if variation in perceived anomaly profitability, holding fixed arbitrageur capital, were the primary driver of variation in our capital measures, we would expect increases in our measure to forecast higher long-short strategy returns. Of course, we cannot observe arbitrageur perceptions, so this evidence is not definitive. ${ }^{38}$

Overall, the evidence presented in this section is consistent with the full set of predictions laid out in Section 1. The growth of arbitrage capital has been associated with a significant reduction in anomaly returns. However, we find evidence consistent with the idea that the arbitrage mechanism is imperfect, suggesting that excess returns associated with anomaly strategies are unlikely to be fully arbitraged away over time.

\section{Conclusion}

The effectiveness of the arbitrage mechanism in real-world financial markets is a central concern in academic finance. We make several novel contributions to the literature on this subject.

First, we provide a novel and general methodology for measuring strategy-level capital. Using time-series variation in the cross-section of short interest, we find clear evidence that suggests that the amount of arbitrage capital devoted to familiar quantitative equity strategies, such as value and momentum, have trended upward over the past twenty-five years. Second, we analyze implications of this growth in arbitrage capital for strategy returns. We provide evidence that this increase in capital has resulted in lower strategy returns, whose signals decay more rapidly

\footnotetext{
${ }^{38}$ For instance, we cannot rule out the possibility that our results are generated by shifting arbitrageur perceptions if those perceptions are systematically incorrect. Specifically, the fact that our capital measures forecast low returns may be explained by shifting arbitrageur perceptions of anomaly profitability, holding fixed arbitrageur capital, if arbitrageur perceptions were negatively correlated with true anomaly profitability.
} 
following portfolio formation. Finally, consistent with theories of limited arbitrage, we show that strategy-level capital flows are influenced by past strategy returns, strategy return volatility, and that arbitrage capital is most limited during times when strategies perform best. This suggests that the growth of arbitrage capital may not completely eliminate returns to these strategies, even in the long run. Taken as a whole, our results suggest that the arbitrage mechanism in real-world financial markets is at once fairly powerful over the long run, even though its effectiveness may sometimes be limited over shorter horizons.

Our methodology for measuring strategy-level capital is likely to be of independent interest to practitioners and policy makers who are interested in detecting "crowded trades" in real time because of the (systemic) risks they may pose. Existing approaches to detecting time variation in crowding analyze changes in the correlation structure of ex post returns (e.g., Adrian (2007); Pericoli and Sbracia (2010); Pojarliev and Levich (2011); Lou and Polk (2012)). However, our approach may be better suited to ex ante surveillance because it relies on changing patterns in arbitrageur positions. 


\section{References}

Adrian, T. 2007. Measuring risk in the hedge fund sector. Federal Reserve Bank of New York Current Issues in Economics and Finance 13(3).

Ang, A., S. Gorovyy, and G. van Inwegen. 2011. Hedge fund leverage. Journal of Financial Economics 102: 102-26.

Ang, A., B. Hodrick, Y. Xing, and X. Zhang. 2006. The cross-section of volatility and expected returns. Journal of Finance 61:259-99.

Aragon, G., and P. Strahan. 2012. Hedge funds as liquidity providers: Evidence from the Lehman bankruptcy. Journal of Financial Economics 103:570-87.

Asquith, P., P. Pathak, and J. Ritter. 2005. Short interest, institutional ownership, and stock returns. Journal of Financial Economics 78: 243-76.

Baker, M., and J. Wurgler. 2006. Investor sentiment and the cross-section of stock returns. Journal of Finance 61:1645-80.

Ball, R. 1978. Anomalies in relationships between securities’ yields and yield-surrogates. Journal of Financial Economics 6:103-26.

Barberis, N., and A. Shleifer. 2003. Style investing. Journal of Financial Economics 68:161-89.

Barberis, N., A. Shleifer, and R. Vishny. 1998. A model of investor sentiment. Journal of Financial Economics 49:307-43.

Basu, S. 1983. The relationship between earnings yield, market value and return for NYSE common stocks: Further evidence. Journal of Financial Economics 12:129-56.

Ben-David, I., M. Drake, and D. Roulstone. Forthcoming. Are stock acquirers overvalued? Identifying mispricing using short interest. Journal of Financial and Quantitative Analysis.

Ben-David, I., F. Franzoni, and R. Moussawi. 2012. Hedge fund stock trading in the financial crisis of 2007-2008. Review of Financial Studies 25:1-54.

Berk, J., and R. Green. 2004. Mutual fund flows and performance in rational markets. Journal of Political Economy 112:1269-95.

Bernard, V., and J. Thomas. 1989. Post-earnings-announcement drift: Delayed price response or risk premium? Journal of Accounting Research 27:1-36.

- 1990. Evidence that stock prices do not fully reflect the implications of current earnings for future earnings. Journal of Accounting and Economics 13:305-40.

Black, F. 1973. Capital market equilibrium with restricted borrowing. Journal of Business 45:444-54.

Boehmer, E., C. Jones, and X. Zhang. 2012. Shackling short sellers: The 2008 shorting ban. Working Paper, Columbia University.

Boyson, N., C. Stahel, and R. Stulz. 2010. Hedge fund contagion and liquidity shocks. Journal of Finance 65:1789-816.

Brunnermeier, M., and L. Pedersen. 2009. Market liquidity and funding liquidity. Review of Financial Studies 22:2201-38.

Brunnermeier, M., and Y. Sannikov. 2012. A macroeconomic model with a financial sector. Working Paper, Princeton University. 
Cao, B., D. Dhaliwal, A. Kolasinski, and A. Reed. 2012. Bears and numbers: Investigating how short sellers exploit and affect earnings-based pricing anomalies. Working Paper, University of Washington.

Cella, C., A. Ellul, and M. Giannetti. 2011. Investors' horizons and the amplification of market shocks. Working Paper.

Chevalier, J., and G. Ellison. 1997. Risk taking by mutual funds as a response to incentives. Journal of Political Economy 105:1167-200.

Cohen, L., K. Diether, and C. Malloy. 2007. Supply and demand shifts in the shorting market. Journal of Finance 62:2061-96.

Cohen, R., and C., Polk. 1996. An investigation of the impact of industry factors in asset-pricing tests. Working Paper, University of Chicago.

Cohen, R., C. Polk, and T. Vuolteenaho. 2003. The value spread. Journal of Finance 58:609-41.

D’Avolio, G. 2002. The market for borrowing stock. Journal of Financial Economics 66:271-306.

Daniel, K., D. Hirshleifer, and A. Subrahmanyam. 1998. Investor psychology and security market under-and overreactions. Journal of Finance 53:1839-85.

Dechow, P., A. Hutton, L. Meulbroek, and R. Sloan. 2001. Short-sellers, fundamental analysis, and stock returns. Journal of Financial Economics 61:77-106.

DeLong, B., A. Shleifer, L. Summers, and R. Waldmann. 1990. Noise trader risk in financial markets. Journal of Political Economy 98:703-38.

Ding, B., M. Getmansky, B. Liang, and R. Wermers. 2009. Share restrictions and investor flows in the hedge fund industry. Working Paper, University of Maryland.

Driscoll, J., and A. Kraay. 1998. Consistent covariance matrix estimation with spatially dependent panel data. Review of Economics and Statistics 80:549-60.

Duffie, D., S. Malamud, and G. Manso. 2009. Information percolation with equilibrium search dynamics. Econometrica 77:1513-74.

Duffie, D., and G. Manso. 2007. Information percolation in large markets. American Economic Review, Papers and Proceedings 97:203-9.

Duffie, D., and B. Strulovici. 2012. Capital mobility and asset pricing. Econometrica 80:2469-509.

Fama, E., and K. French. 1992. The cross-section of expected stock returns. Journal of Finance 47:427-65.

- 1993. Common risk factors in the returns on stocks and bonds. Journal of Financial Economics 33:3-56.

Fostel, A., and J. Geanakoplos. 2008. Leverage cycles and the anxious economy. American Economic Review 98:1211-44.

Frazzini, A., and L. Pedersen. 2011. Betting against beta. Working Paper, New York University.

Gabaix, X., A. Krishnamurthy, and O. Vigneron. 2007. Limits of arbitrage: Theory and evidence from the mortgage-backed securities market. Journal of Finance 62:557-95.

Garleanu, N., and L. Pedersen. 2011. Margin-based asset pricing and deviations from the law of one price. Review of Financial Studies 24:1980-2022.

Geanakoplos, J. 2010. The leverage cycle. In NBER macroeconomic annual 2009, vol. 24, pp. 1-65. Eds. D. Acemoglu, K. Rogoff and M. Woodford. Chicago: University of Chicago Press. 
Geczy, C., D. Musto, and A. Reed. 2002. Stocks are special too: An analysis of equity market lending. Journal of Financial Economics 66:241-69.

Goetzmann, W., and M. Massa. 2003. Index funds and stock market growth. Journal of Business 76:128.

Goldman Sachs. 2008. Goldman Sachs hedge fund trend monitor. February 20.

Graham, B., and D. Dodd. 1934. Security analysis. New York: McGraw-Hill.

Greenwood, R., and D. Thesmar. 2011. Stock price fragility. Journal of Financial Economics 102:471-90.

Gromb, D., and D. Vayanos. 2010. Limits of arbitrage: The state of the theory. Annual Review of Financial Economics 2:251-75.

Hanson, S., and A. Sunderam. 2013. Are there too many safe securities? Securitization and the incentives for information production. Journal of Financial Economics 108:565-84.

Hau, H., and S. Lai. 2012. The role of equity funds in the financial crisis propagation. Working Paper.

He, Z., and A. Krishnamurthy. 2013. Intermediary asset pricing. American Economic Review 103:73270 .

Hirshleifer, D., S. Teoh, and J. Yu. 2011. Short arbitrage, return asymmetry and the accrual anomaly. Review of Financial Studies 24:2429-61.

Holmstrom, B. 1979. Moral hazard and observability. Bell Journal of Economics 10:74-91.

Holmstrom, B., and J. Tirole. 1997. Financial intermediation, loanable funds and the real sector. Quarterly Journal of Economics 112:663-91

Hong, H., and D. Sraer. 2012. Speculative betas. Working Paper, Princeton University.

Hong, H., and J. Stein. 1999. A unified theory of underreaction, momentum trading and overreaction in asset markets. Journal of Finance 54:2143-84.

Jegadeesh, N. 1990. Evidence of predictable behavior of security returns. Journal of Finance 45:88198.

Jegadeesh, N. and S. Titman. 1993. Returns to buying winners and selling losers: Implications for stock market efficiency. Journal of Finance 48:65-91.

Khandani, A., and A. Lo. 2007. What happened to the quants in August 2007? MIT Journal of Investment Management 5:29-78.

Kiyotaki, N., and J. Moore. 1997. Credit cycles. Journal of Political Economy 105:211-48.

Kolasinski, A., A. Reed, and M. Ringgenberg. 2013. A multiple lender approach to understanding supply and search in the equity lending market. Journal of Finance 68:559-95.

Lamont, O., and J. Stein. 2004. Aggregate short interest and market valuations. American Economic Review Papers and Proceedings 94:29-32.

Lewellen, J. 2011. Institutional investors and the limits of arbitrage. Journal of Financial Economics 102:62-80.

Lo, A. 2004. The adaptive markets hypothesis: Market efficiency from an evolutionary perspective. Journal of Portfolio Management 30:15-29.

Lou, D., and C. Polk. 2012. Co-momentum. Working Paper, London School of Economics. 
McLean, D., and J. Pontiff. 2012. Does academic research destroy return predictability? Working Paper, Boston College.

Nagel, S. 2005. Short sales, institutional investors, and the cross-section of stock returns. Journal of Financial Economics 78:277-309.

—. 2012. Evaporating liquidity. Review of Financial Studies 25: 2005-39.

Newey, W., and K. West. 1987. A simple, positive semi-definite, heteroskedasticity and autocorrelation consistent covariance matrix. Econometrica 55:703-8.

Pedersen, L. 2009. When everyone runs for the exit. International Journal of Central Banking 5:17799.

Pericoli, M. and M. Sbracia. 2010. Crowded trades among hedge funds. Working Paper, Banca d'Italia.

Pojarliev, M., and R. Levich. 2011. Detecting crowded trades in currency funds. Financial Analysts Journal 67:26-39.

Rosenberg, B., K. Reid, and R. Lanstein. 1985. Persuasive evidence of market inefficiency. Journal of Portfolio Management 11:9-17.

Savor, P., and M. Gamboa-Cavazos. 2011. Holding on to your shorts: When do short sellers retreat? Working Paper, University of Pennsylvania.

Shleifer, A., and R. Vishny. 1997. The limits of arbitrage. Journal of Finance 52:35-55.

—. 2011. Fire sales in finance and macroeconomics. Journal of Economic Perspectives 25:29-48.

Sirri, E., and P. Tufano. 1998. Costly search and mutual fund flows. Journal of Finance 53:1589-622.

Sloan, R. 1996. Do stock prices fully reflect information in accruals and cash flows about future earnings? Accounting Review 71:289-315.

Stattman, D. 1980. Book values and stock returns. Chicago MBA: A Journal of Selected Papers 4:2545.

Stein, J. 2009. Presidential address: Sophisticated investors and market efficiency. Journal of Finance 64:1517-48.

Teo, M., and S. Woo. 2004. Style effects in the cross-section of stock returns. Journal of Financial Economics 74:367-98.

Thompson, S. 2011. Simple formulas for standard errors that cluster by both firm and time. Journal of Financial Economics 99:1-10.

Wang, A., and L. Zheng. 2008. Aggregate hedge fund flows and asset returns. Working Paper, University of California, Irvine. 


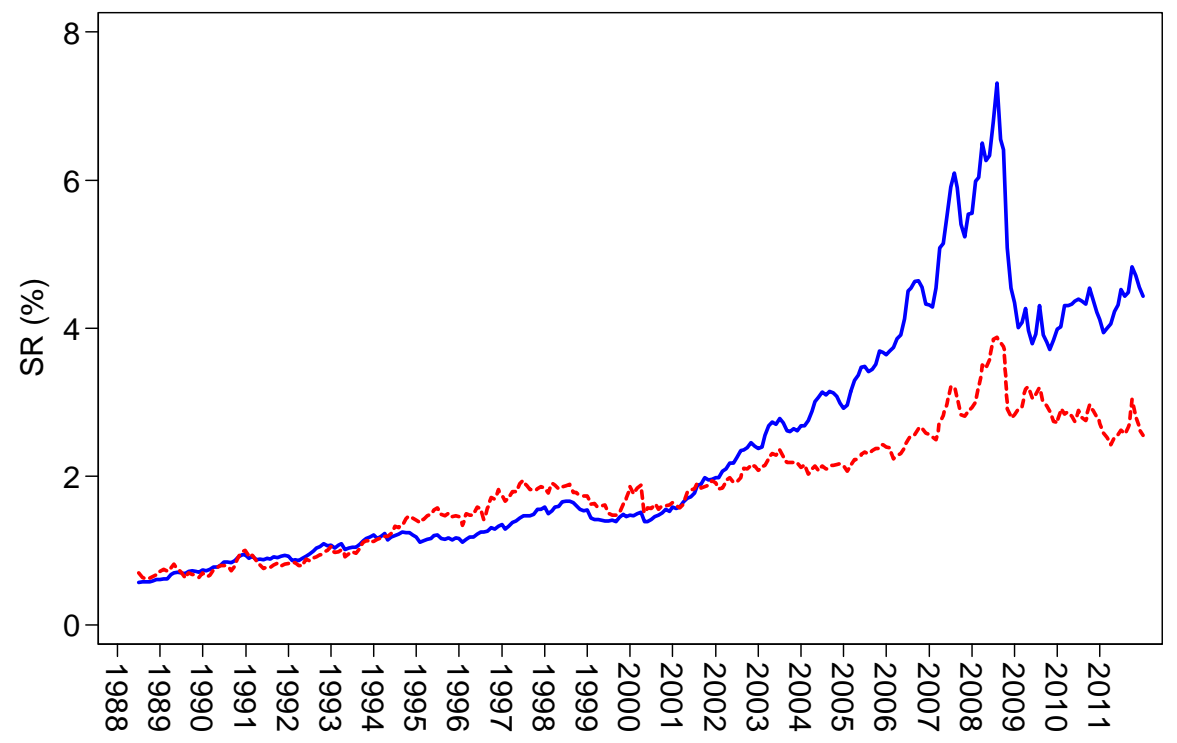

Equal-weighted average --------- Value-weighted average

\section{Figure 1}

Average short interest ratios, 1988-2011

This figure plots the monthly equal- and value- (i.e., market equity) weighted average short interest ratio for all stocks in our sample. The short interest ratio for stock $i$ in month $t$ is defined as $S R_{i t}=S H O R T_{i t} / S H R O U T_{i t}$, where $S H O R T_{i t}$ is short interest as of the midmonth reporting date, and $S H R O U T_{i t}$ is shares outstanding as of the reporting date.

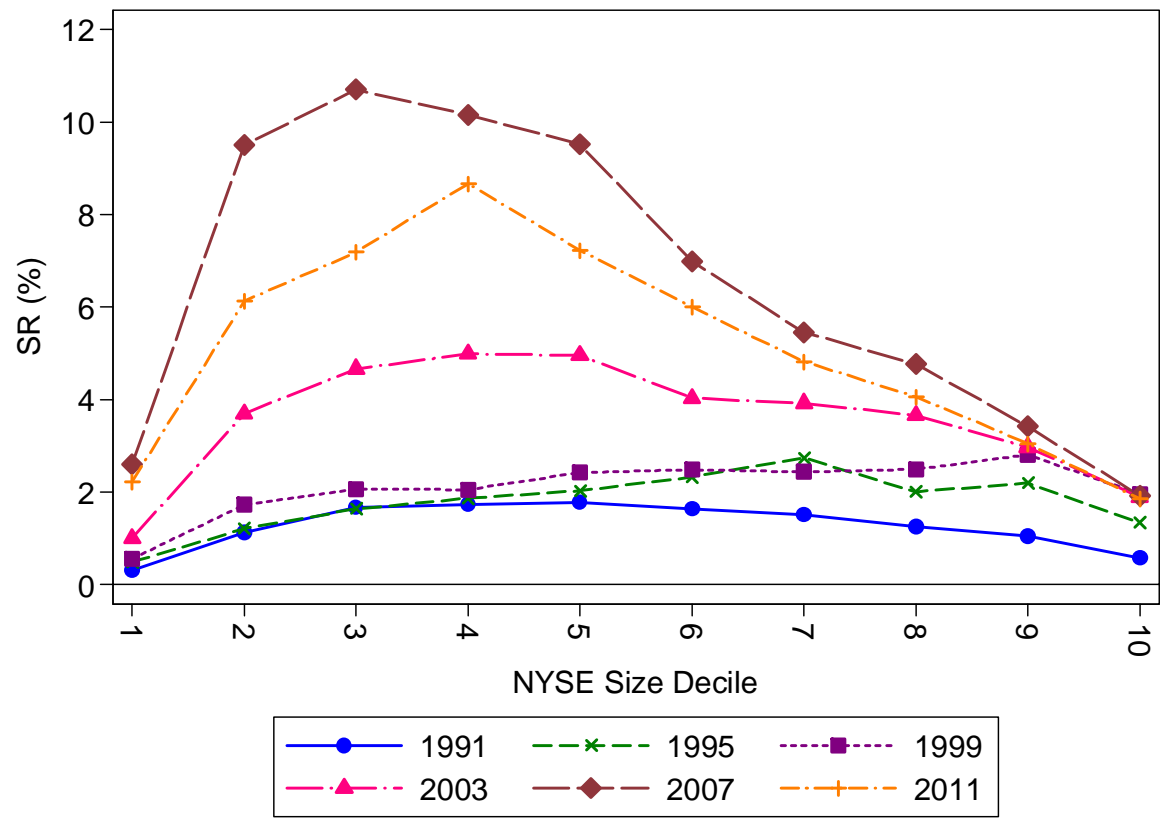

\section{Figure 2}

Average short interest ratios by size decile

This figure shows the average short interest ratio by NYSE size decile as of the year-ends 1991, 1995, 1999, 2003, 2007, and 2011. 
Panel A: $S R$ for stocks entering $B / M$ decile 1 (i.e., extreme growth stocks)
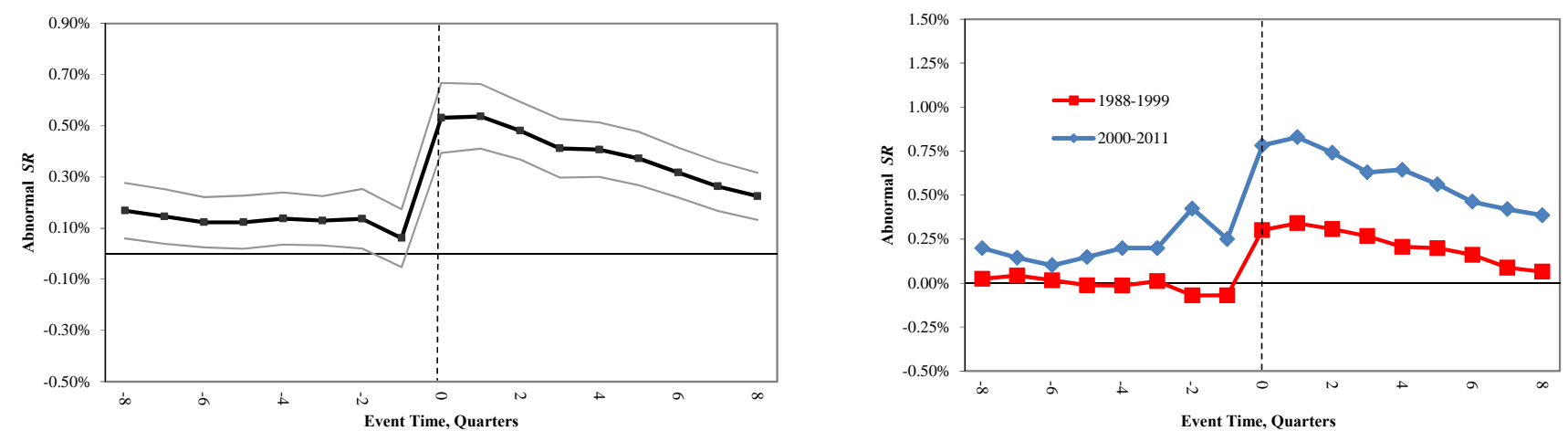

Panel B: SR for stocks entering momentum decile 1 (i.e., past return “losers”)
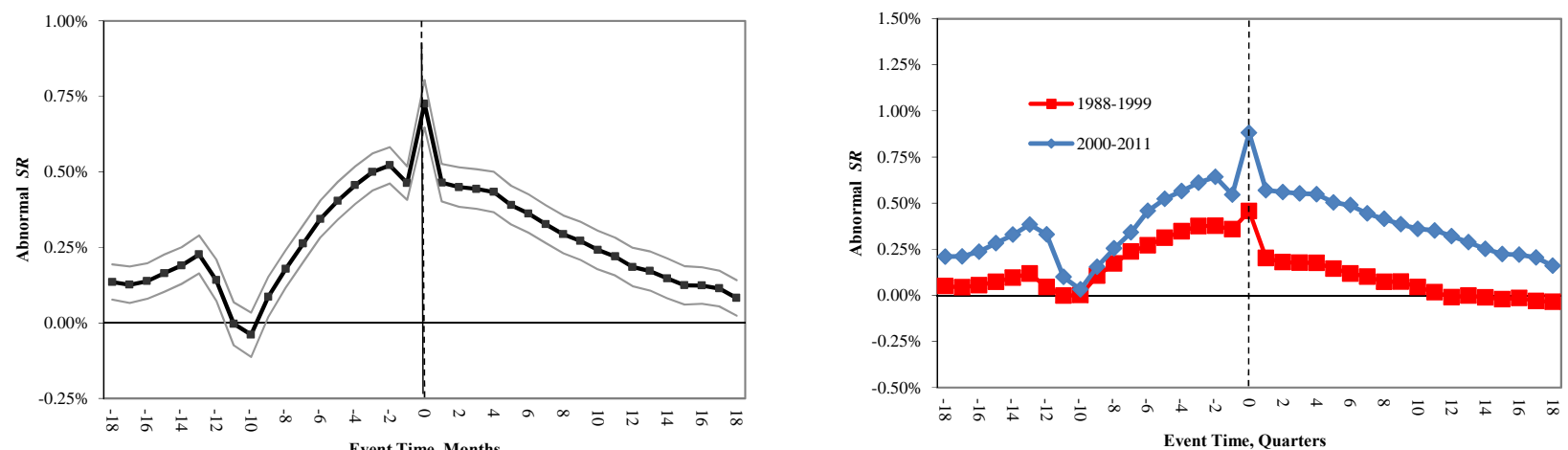

Figure 3

Short interest for stocks entering the extreme $B / M$ (growth) or momentum (loser) deciles

The figure plots the "event-time" path of short interest for stocks entering the extreme growth or momentum deciles. Panel A plots the $\kappa^{j}$ for $j=+8, \ldots, 0, . .,-8$ from estimating the following quarterly panel regression

$$
\begin{aligned}
S R_{i t}=\kappa^{+8} 1_{i t}^{+8}\{B / M\}+\cdots & +\kappa^{0} 1_{i t}^{0}\{B / M\}+\cdots+\kappa^{-8} 1_{i t}^{-8}\{B / M\} \\
& +\boldsymbol{\kappa}^{\text {SIZE }} \cdot \mathbf{1}_{i t}^{\text {SIZE }}+\boldsymbol{\kappa}^{\text {MOM }} \cdot \mathbf{1}_{i t}^{\text {MOM }}+\boldsymbol{\beta}^{\prime} \mathbf{x}_{i t}+\text { Stock }_{i}+\text { Time }_{t}+\varepsilon_{i t} .
\end{aligned}
$$

The $1_{i t}^{+k}\{B / M\}$ dummy indicates that stock $i$ will enter the lowest $B / M$ decile in $k$ quarters (i.e., at $t+k$ ), and the $1_{i t}^{-k}\{B / M\}$ dummy indicates that stock $i$ exited the lowest $B / M$ decile $k$ quarters ago. If a firm has a "spell" of consecutive quarters in the lowest $B / M$ decile, the $1_{i t}^{+k}\{B / M\}$ dummies are coded relative to the first quarter in the spell. Similarly, the $1_{i t}^{-k}\{B / M\}$ dummies are coded relative to the last quarter in the spell. Thus, the event-time path is identified using transitions into and out of the extreme decile. We also include dummies for the number of consecutive quarters that a stock has spent in the lowest $B / M$ decile. We control for size $\left(\mathbf{1}_{i t}^{\text {SIZE }}\right)$ and momentum $\left(\mathbf{1}_{i t}^{\text {MOM }}\right)$ decile dummies as well as a vector $\left(\mathbf{x}_{i t}\right)$ of additional controls: institutional ownership, three-month turnover, trailing twelve-month return volatility, stock exchange, and a convertible outstanding dummy. Finally, the regression also includes a full set of stock and time fixed effects. We draw $95 \%$ confidence bands around the estimates using standard errors that cluster by both stock and time as done by Thompson (2011). Panel B repeats this for the analogous specification for stocks entering the extreme momentum (i.e., past "loser") decile. Because momentum deciles are updated each month, this regression is run using monthly data. 

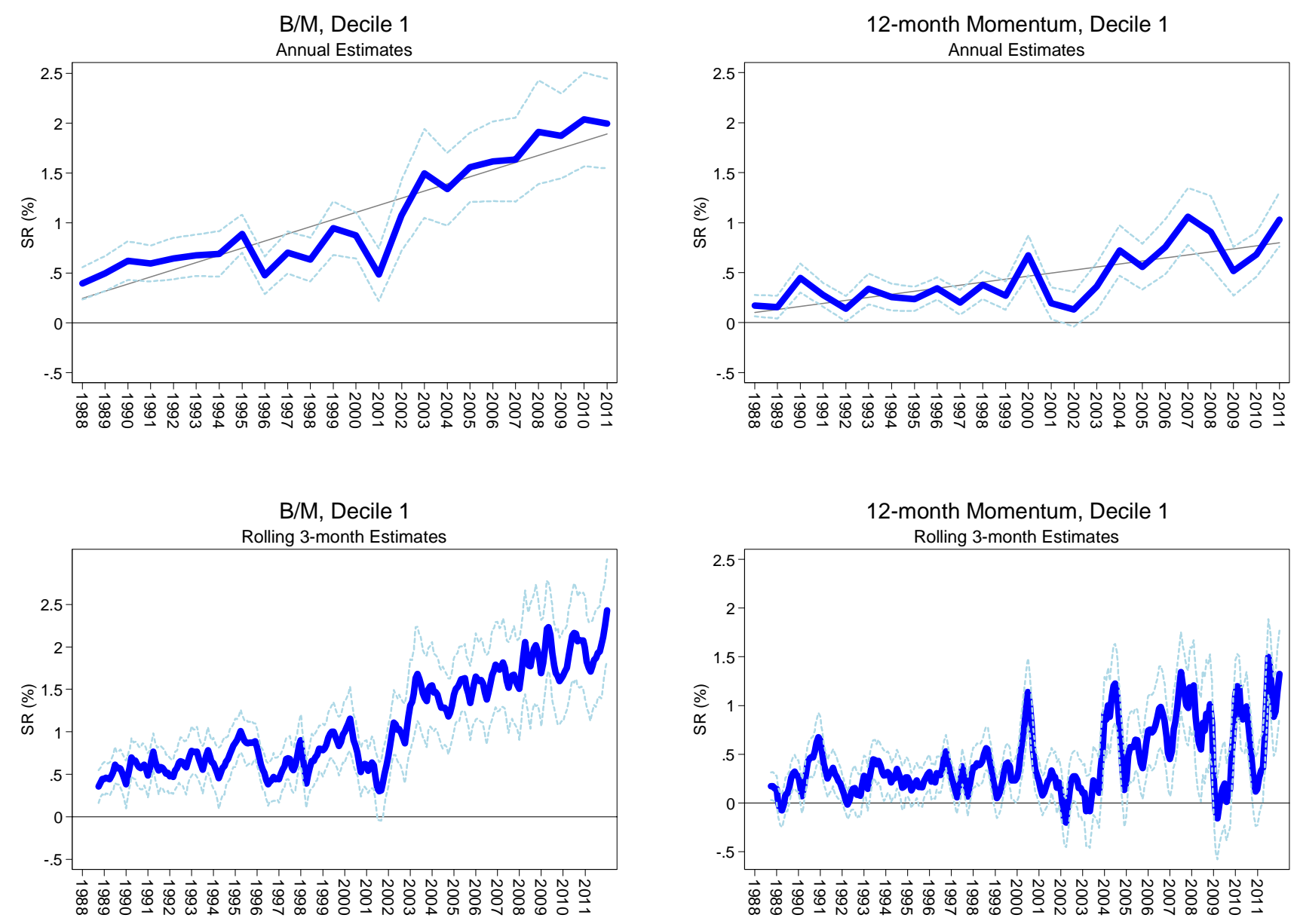

Figure 4

Estimated capital intensities for value and momentum strategies, 1988-2011

The figure plots the time series of estimated coefficients on the extreme growth decile $\left(\hat{\kappa}_{t}^{B / M(1)}\right)$ and extreme momentum loser decile $\left(\hat{\kappa}_{t}^{M O M(1)}\right)$ from the following specification

$$
S R_{i t}=\alpha_{t}+\boldsymbol{\kappa}_{t}^{B / M} \cdot \mathbf{1}_{i t}^{B / M}+\boldsymbol{\kappa}_{t}^{M O M} \cdot \mathbf{1}_{i t}^{M O M}+\boldsymbol{\kappa}_{t}^{S I Z E} \cdot \mathbf{1}_{i t}^{S I Z E}+\boldsymbol{\beta}_{t}^{\prime} \mathbf{x}_{i t}+\varepsilon_{i t} .
$$

In the top row, these regressions are estimated annually, pooling all observations in a given year. In the bottom row, these regressions are estimated on a rolling quarterly basis, pooling all observations in a given three-month period. Both specifications also include a full set of month fixed effects. The dashed lines are confidence intervals for the estimated coefficients, computed using standard errors that cluster by firm (i.e., they are robust to serial correlation at the firm level). 


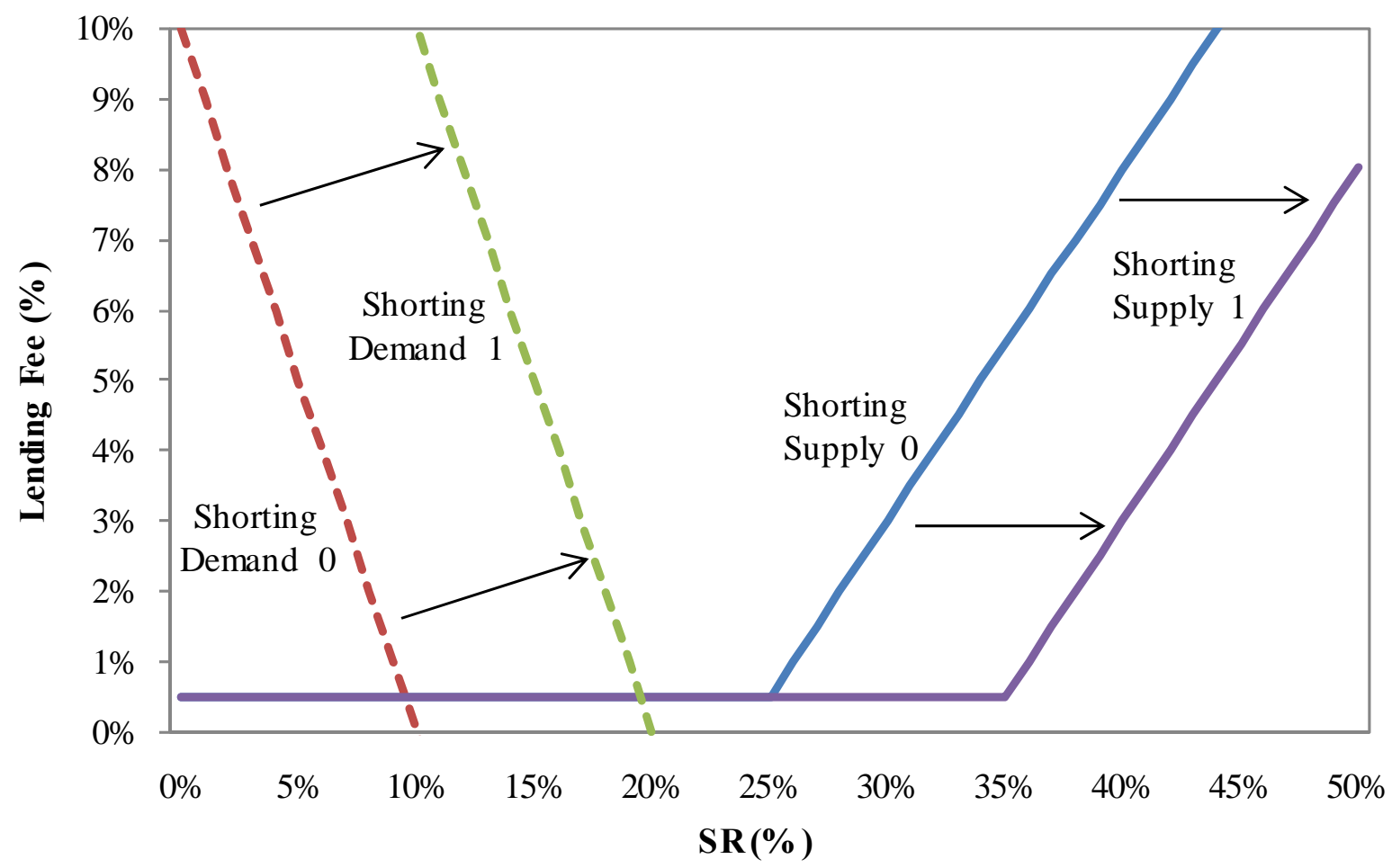

Figure 5

Stylized depiction of the equity lending market

The figure shows a shorting demand curve and share lending supply curve. Short interest $S R_{i t}$ is on the horizontal access, and share lending fees are on the vertical access. D'Avolio (2002) finds that shorting supply curves are kinked, are highly elastic for low values of $S R_{i t}$, and are inelastic beyond that kink. The location of the kink depends on the fraction of a firm's shares that are held by institutional owners with active share lending programs. The figure shows the effect of an outward shift in both demand and supply for a stock that initially has a high level of institutional ownership. The figure suggests that short interest in stocks with high institutional ownership is unlikely to be affected by loosening supply constraints. 


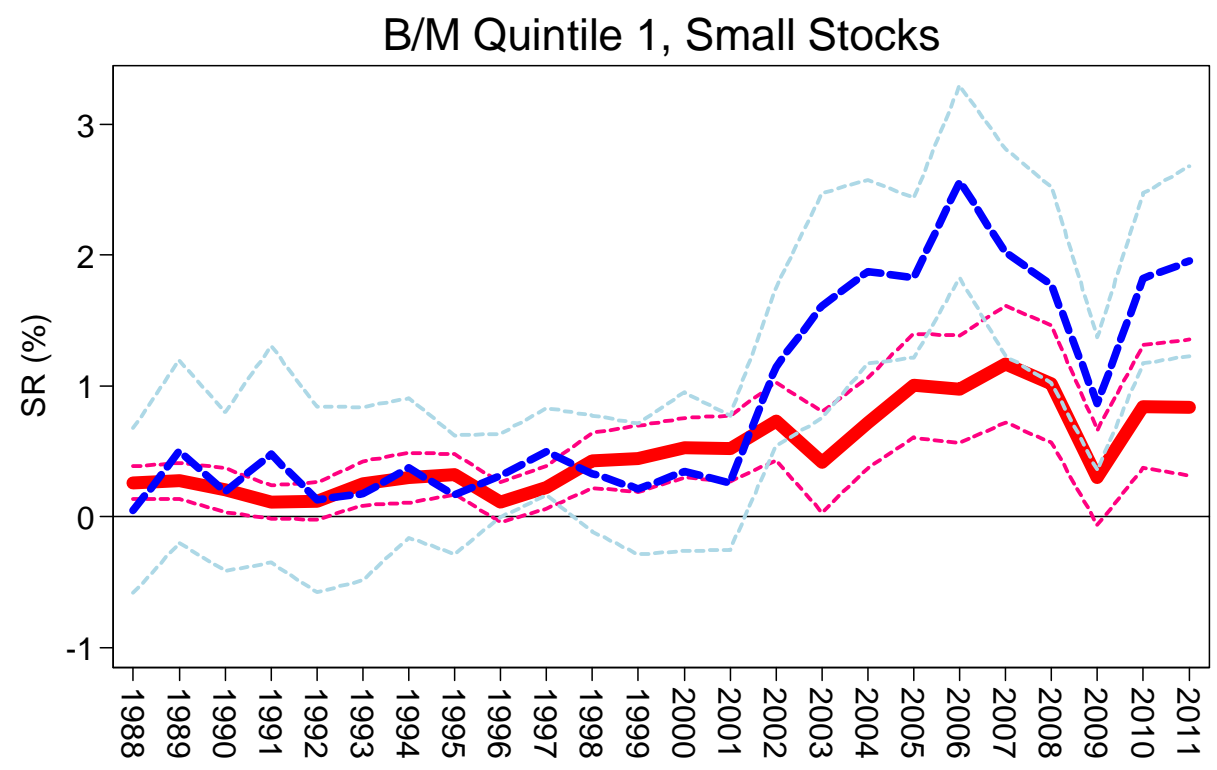

Low 10

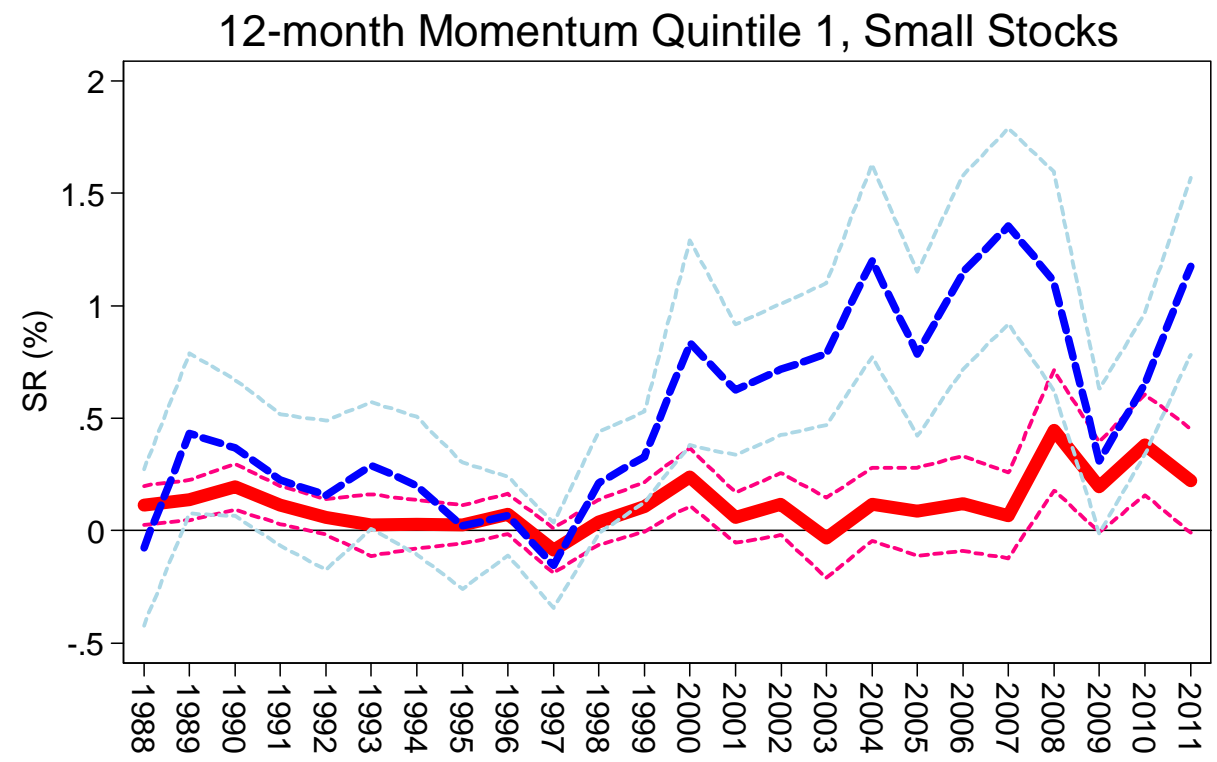

Low IO

High 10

\section{Figure 6}

\section{Capital intensities for small stocks by institutional ownership}

The figure plots the time series of estimated coefficients on the extreme growth quintile and momentum quintile, allowing for separate effects by size and institutional ownership group. We group stocks into small (size deciles 1 and 2), medium (deciles 35), and big (deciles 6-10) stocks (me $\in\{S, M, B\}$ ). We use a fixed ownership cutoff of $30 \%$, so stocks with $I O_{i t}<30 \%$ are considered to have low institutional ownership. Thus, we have a set of $6=3 \times 2$ size by $I O$ bins in each cross-section. For each cross-section, we run our baseline specification, allowing each of the six size by $I O$ bins to have its own intercept $\left(\alpha_{t(m e, i o)}\right)$ and its own coefficients on the $B / M$ and momentum quintile dummies $\left(\boldsymbol{\kappa}_{t(m e, i o)}^{B / M}\right.$ and $\left.\boldsymbol{\kappa}_{t(m e, i o)}^{M O M}\right)$.

$S R_{i t}=\sum_{i o \in\{L, H\}} \sum_{m e \in\{S, M, B\}}\left(\alpha_{t(m e, i o)}+\mathbf{\kappa}_{t(m e, i o)}^{B / M} \cdot \mathbf{1}_{i t}^{B / M}+\mathbf{\kappa}_{t(m e, i o)}^{M O M} \cdot \mathbf{1}_{i t}^{M O M}\right) \times 1\left\{M E_{i t} \in m e\right\} \times 1\left\{I O_{i t} \in i o\right\}+\boldsymbol{\beta}_{t}^{\prime} \mathbf{x}_{i t}+\varepsilon_{i t}$. 


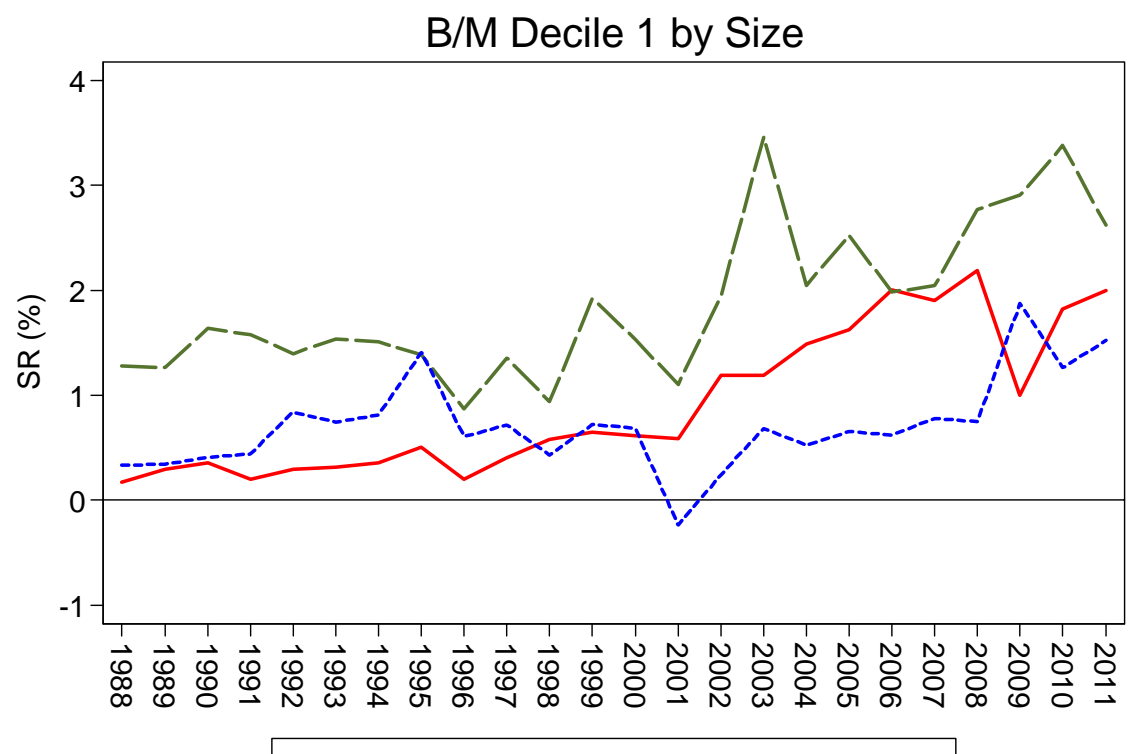

Small - - Med.

Big

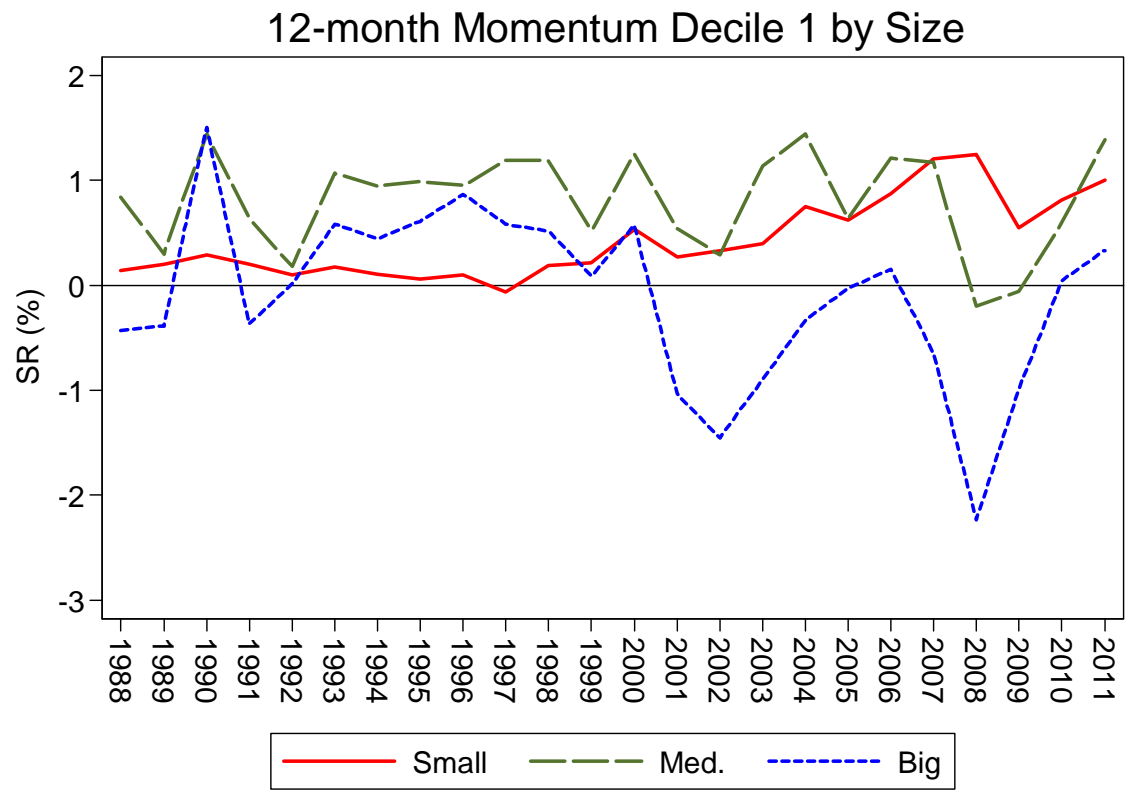

Figure 7

Size interactions

The figure plots the time series of estimated coefficients on the extreme growth decile and momentum decile, allowing for separate effects by size group

$$
\begin{aligned}
S R_{i t}=\alpha_{t} & +\mathbf{\kappa}_{t}^{B / M, S M A L L} \cdot\left(\mathbf{1}_{i t}^{B / M} \times 1_{i t}^{S M A L L}\right)+\mathbf{\kappa}_{t}^{B / M, M E D} \cdot\left(\mathbf{1}_{i t}^{B / M} \times 1_{i t}^{M E D}\right)+\mathbf{K}_{t}^{B / M, B I G} \cdot\left(\mathbf{1}_{i t}^{B / M} \times 1_{i t}^{B I G}\right) \\
& +\mathbf{\kappa}_{t}^{M O M, S M A L L} \cdot\left(\mathbf{1}_{i t}^{M O M} \times 1_{i t}^{S M A L L}\right)+\mathbf{\kappa}_{t}^{M O M, M E D} \cdot\left(\mathbf{1}_{i t}^{M O M} \times 1_{i t}^{M E D}\right)+\mathbf{\kappa}_{t}^{M O M, B I G} \cdot\left(\mathbf{1}_{i t}^{M O M} \times 1_{i t}^{B I G}\right) \\
& +\mathbf{\kappa}_{t}^{S I Z E} \cdot \mathbf{1}_{i t}^{S I Z E}+\boldsymbol{\beta}_{t}^{\prime} \mathbf{x}_{i t}+\varepsilon_{i t} .
\end{aligned}
$$

These regressions are estimated annually. For instance, the coefficient for $B / M$ decile 1 for small stocks shows the boost in $S R$ (relative to stocks in $B / M$ decile 5 ) among small stocks. 

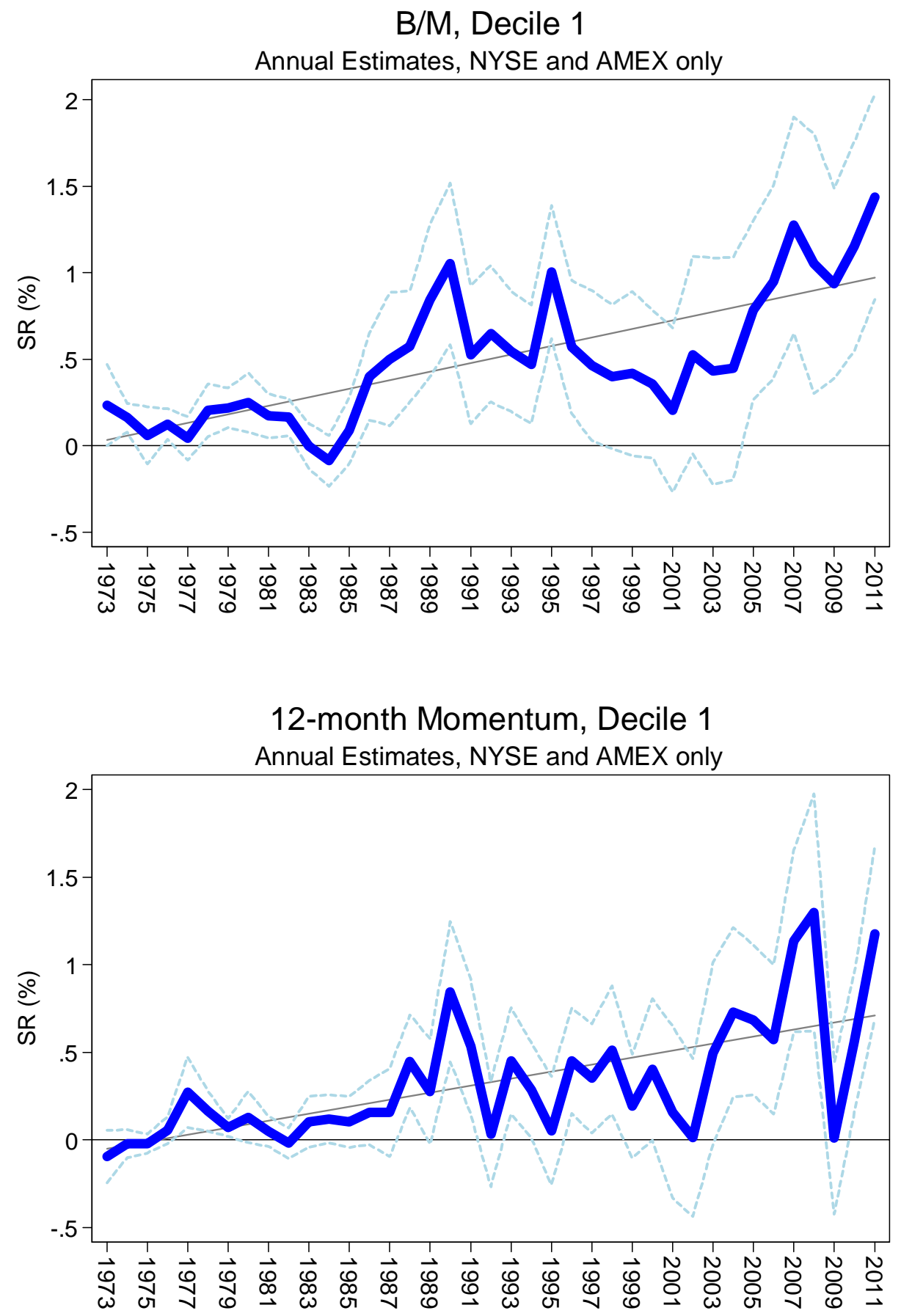

Figure 8

Estimated capital intensities for value and momentum, NYSE and AMEX stocks only, 1973-2011

The figure plots the time series of estimated coefficients on the extreme growth decile $\left(\hat{\kappa}_{t}^{B / M(1)}\right)$ and extreme momentum loser decile $\left(\hat{\kappa}_{t}^{M O M(1)}\right)$ from the following specification

$$
S R_{i t}=\alpha_{t}+\boldsymbol{\kappa}_{t}^{B / M} \cdot \mathbf{1}_{i t}^{B / M}+\boldsymbol{\kappa}_{t}^{M O M} \cdot \mathbf{1}_{i t}^{M O M}+\boldsymbol{\kappa}_{t}^{S I Z E} \cdot \mathbf{1}_{i t}^{S I Z E}+\boldsymbol{\beta}_{t}^{\prime} \mathbf{x}_{i t}+\varepsilon_{i t} \cdot
$$

The regressions are estimated annually, pooling all observations in a given year, and using NYSE and AMEX stocks only. The specifications include a full set of month fixed effects. The dashed lines are confidence intervals for the estimated coefficients, computed using standard errors that cluster by firm. 
Table 1

Summary statistics

\begin{tabular}{|c|c|c|c|c|c|c|}
\hline & $\overline{\mathrm{N}}$ & Mean & Median & SD & Min & Max \\
\hline \multicolumn{7}{|c|}{ Panel A: Data for stock-level, cross-sectional short interest regressions (firm-months, 1988-2011) } \\
\hline Short interest ratio, $S R,(\%)$ & $1,299,210$ & 2.26 & 0.53 & 4.17 & 0.00 & 65.53 \\
\hline Book-to-market & $1,299,210$ & 0.75 & 0.58 & 0.72 & 0.01 & 12.84 \\
\hline 12-month momentum (\%) & $1,299,210$ & 14.26 & 3.87 & 80.46 & -99.90 & $9,857.14$ \\
\hline Institutional ownership (\%) & $1,299,210$ & 38.67 & 33.55 & 30.57 & 0.00 & 148.05 \\
\hline Turnover (\%) & $1,299,210$ & 7.86 & 4.42 & 10.29 & 0.01 & 144.16 \\
\hline Return volatility (\%) & $1,299,210$ & 14.72 & 12.07 & 10.37 & 0.85 & 110.81 \\
\hline NASDAQ dummy & $1,299,210$ & 0.64 & 1.00 & 0.48 & 0.00 & 1.00 \\
\hline NYSE dummy & $1,299,210$ & 0.29 & 0.00 & 0.45 & 0.00 & 1.00 \\
\hline Convertible dummy & $1,299,210$ & 0.17 & 0.00 & 0.38 & 0.00 & 1.00 \\
\hline \multicolumn{7}{|c|}{ Panel B: Data for time-series regressions (quarterly, 1988Q3-2011Q4) } \\
\hline$\hat{\kappa}^{B / M}$ (bps) & 94 & 107.82 & 87.07 & 56.02 & 33.77 & 243.30 \\
\hline$\hat{\kappa}^{M O M}(\mathrm{bps})$ & 94 & 42.73 & 30.21 & 35.67 & -20.31 & 149.60 \\
\hline$H M L(\%)$ & 94 & 0.75 & 0.47 & 6.42 & -19.17 & 25.00 \\
\hline$U M D(\%)$ & 94 & 2.00 & 1.91 & 8.85 & -39.83 & 26.05 \\
\hline MKTRF (\%) & 94 & 1.64 & 2.54 & 8.58 & -23.99 & 20.16 \\
\hline$\sigma^{H M L}$ & 94 & 7.70 & 6.18 & 4.87 & 2.87 & 23.83 \\
\hline$\sigma^{U M D}$ & 94 & 10.57 & 7.50 & 8.32 & 2.49 & 45.67 \\
\hline$\sigma^{M K T R F}$ & 94 & 15.62 & 12.59 & 8.99 & 6.27 & 66.96 \\
\hline EHEDGE (\%) & 88 & 3.23 & 2.89 & 5.70 & -12.69 & 21.13 \\
\hline TED (\%) & 94 & 55.22 & 43.06 & 47.05 & 9.85 & 335.58 \\
\hline
\end{tabular}

This table reports summary statistics for the main variables used in this paper. Panel A reports summary statistics for the data used in the stock-level, cross-sectional short interest regressions. The short interest ratio for stock $i$ in month $t$ is defined as $S R_{i t}=S H O R T_{i t} / S H R O U T_{i t}$, where $S H O R T_{i t}$ is short interest as of the midmonth reporting date, and SHROUT it is shares outstanding as of the reporting date from CRSP. Our timing conventions ensure all firm characteristics are publicly available as of the date on which short interest is measured. $B / M$ deciles are refreshed quarterly, allowing for at least three months between the fiscal quarter-end when book equity is measured and the sort date. For instance, short interest observations for July, August, and September are associated with $B / M$ sorts performed at the end of June. These book-to-market ratios are based on market equity as of the end of the prior quarter (March) and on book-equity from fiscal quarters ending in the prior calendar quarter (January, February, or March). This is the quarterly analog of the familiar timing conventions established by Fama and French (1992). Book equity is defined as stockholder's equity, plus balance sheet deferred taxes and investment tax credits (when available), minus the book value of preferred stock. We also sort firms on the basis of industry-adjusted $B / M$ using the 48 FamaFrench (1997) industries. Specifically, we subtract the eight-quarter moving average of aggregate industry $B / M$ (industry book over industry market value) from each individual firm's book-to-market ratio. Twelve-month return momentum deciles are based on cumulative returns from months $t-12$ to $t-1$. That is, we skip a month when computing past returns to avoid contaminating over measures with the short-term reversal phenomenon documented by Jegadeesh (1990). Momentum deciles are refreshed each month. For instance, short interest observations for July are associated with momentum sorts performed at the end of June. These sorts are based on the eleven-month cumulative returns from July (of the previous year) through May. We also compute the fraction of shares held by 13-F institutions as of the most recent quarter-end, the three-month moving average of share turnover (volume over shares outstanding), trailing twelve-month return volatility, exchange dummies (i.e., a NASDAQ dummy and an NYSE dummy), and a dummy that indicates whether a firm has convertible securities outstanding. All continuous variables are winsorized in each cross-section at the $0.5 \%$ and $99.5 \%$-tiles. Panel B reports summary statistics for our quarterly time-series regressions. $\hat{\kappa}^{B / M}$ and $\hat{\kappa}^{M O M}$ are our baseline value and momentum capital measures in basis points (bps). Quarterly factor returns for $H M L, U M D$, and $M K T R F$ are from Kenneth French's Web site. We also compute rolling factor volatilities, $\sigma^{H M L}$, $\sigma^{U M D}$, and $\sigma^{M K T R F}$, as the standard deviation of daily factor returns during quarter $t$. To proxy for the returns to hedge funds more generally, we use the return indices for "Equity Hedge" (EHEDGE) hedge funds available from Hedge Fund Research (HFR). The quarterly returns are in percentages and our factor volatility measures are in annualized percentages. The TED spread is the difference between the rate on three-month Eurodollar deposits (i.e., three-month LIBOR) and the yield on the three-month Treasury bill. Both rates are taken from the Federal Reserve H.15 release. 
Table 2

The level of arbitrage capital and future strategy returns

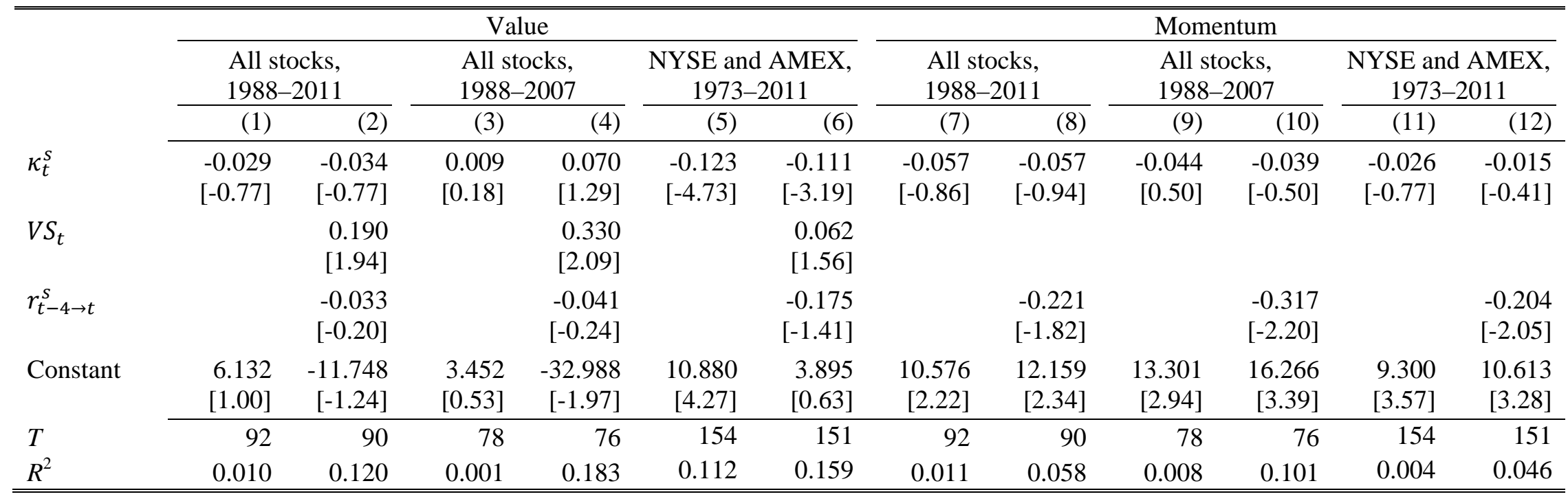

This table shows time-series forecasting regressions of the form

$$
r_{t \rightarrow t+4}^{s}=\mu+\beta \cdot \kappa_{t}^{s}+\varepsilon_{t \rightarrow t+4}^{s},
$$

where $r_{t \rightarrow t+4}^{S}$ is the four-quarter annual return for strategy $s$ from quarter $t$ to quarter $t+4 . V S_{t}$ is the value spread computed as in Cohen, Polk, and Vuolteenaho (2003). $t$-statistics are shown in brackets and are computed using Newey-West (1987) standard errors allowing for serial correlation at up to six quarterly lags. We show results based on capital measures for all stocks from 1988Q3 to 2011Q2 (the last quarter for which we can compute four-quarter future annual returns), all stocks from 1988Q3 to 2007Q4, and NYSE and AMEX stocks only from 1973Q1 to 2011Q2. 
Table 3

Panel results

\begin{tabular}{|c|c|c|c|c|c|c|c|c|}
\hline & \multicolumn{4}{|c|}{$1988-2011$} & \multicolumn{4}{|c|}{$1988-2007$} \\
\hline & $(1)$ & $(2)$ & (3) & (4) & (5) & (6) & $(7)$ & (8) \\
\hline \multicolumn{9}{|c|}{ Panel A: The level of arbitrage capital and future strategy returns } \\
\hline$\kappa_{t}^{S}$ & $\begin{array}{l}-0.044 \\
{[-4.10]}\end{array}$ & $\begin{array}{l}-0.047 \\
{[-4.57]}\end{array}$ & $\begin{array}{r}-0.035 \\
{[-2.01]}\end{array}$ & $\begin{array}{l}-0.038 \\
{[-2.07]}\end{array}$ & $\begin{array}{l}-0.037 \\
{[-2.81]}\end{array}$ & $\begin{array}{r}-0.039 \\
{[-3.39]}\end{array}$ & $\begin{array}{l}-0.012 \\
{[-0.63]}\end{array}$ & $\begin{array}{c}-0.013 \\
{[-0.67]}\end{array}$ \\
\hline$r_{t-4 \rightarrow t}^{S}$ & & $\begin{array}{l}-0.104 \\
{[-1.07]}\end{array}$ & & $\begin{array}{l}-0.130 \\
{[-1.32]}\end{array}$ & & $\begin{array}{l}-0.081 \\
{[-0.64]}\end{array}$ & & $\begin{array}{l}-0.140 \\
{[-1.12]}\end{array}$ \\
\hline Constant & $\begin{array}{r}8.189 \\
{[5.93]}\end{array}$ & $\begin{array}{c}8.922 \\
{[4.97]}\end{array}$ & $\begin{array}{r}7.829 \\
{[4.74]}\end{array}$ & $\begin{array}{c}8.762 \\
{[4.13]}\end{array}$ & $\begin{array}{r}9.243 \\
{[8.41]}\end{array}$ & $\begin{array}{c}9.867 \\
{[5.04]}\end{array}$ & $\begin{array}{r}8.339 \\
{[5.39]}\end{array}$ & $\begin{array}{r}9.406 \\
{[4.23]}\end{array}$ \\
\hline$N$ & 460 & 450 & 460 & 450 & 390 & 380 & 390 & 380 \\
\hline Strategy FE & no & no & yes & yes & no & no & yes & yes \\
\hline$R^{2}$ & 0.021 & 0.031 & 0.043 & 0.056 & 0.012 & 0.018 & 0.071 & 0.085 \\
\hline \multicolumn{9}{|c|}{ Panel B: The level of arbitrage capital and the decay of strategy profits following portfolio formation } \\
\hline$\kappa_{t}^{S}$ & $\begin{array}{l}-0.215 \\
{[2.39]}\end{array}$ & $\begin{array}{l}-0.113 \\
{[1.50]}\end{array}$ & $\begin{array}{l}-0.233 \\
{[2.45]}\end{array}$ & $\begin{array}{c}0.000 \\
{[0.00]}\end{array}$ & $\begin{array}{l}-0.250 \\
{[1.93]}\end{array}$ & $\begin{array}{c}-0.156 \\
{[1.27]}\end{array}$ & $\begin{array}{c}-0.235 \\
{[1.60]}\end{array}$ & $\begin{array}{c}-0.016 \\
{[0.10]}\end{array}$ \\
\hline Trend & & $\begin{array}{r}-0.446 \\
{[4.85]}\end{array}$ & & $\begin{array}{l}-0.526 \\
{[4.34]}\end{array}$ & & $\begin{array}{c}-0.415 \\
{[3.36]}\end{array}$ & & $\begin{array}{l}-0.518 \\
{[3.07]}\end{array}$ \\
\hline Constant & $\begin{array}{r}0.869 \\
{[11.41]} \\
\end{array}$ & $\begin{array}{r}1.044 \\
{[16.38]} \\
\end{array}$ & $\begin{array}{r}0.877 \\
{[12.66]} \\
\end{array}$ & $\begin{array}{r}1.036 \\
{[17.44]} \\
\end{array}$ & $\begin{array}{r}0.911 \\
{[11.18]}\end{array}$ & $\begin{array}{r}1.046 \\
{[15.18]}\end{array}$ & $\begin{array}{r}0.905 \\
{[11.21]}\end{array}$ & $\begin{array}{r}1.038 \\
{[16.57]}\end{array}$ \\
\hline$N$ & 465 & 465 & 465 & 465 & 390 & 390 & 390 & 390 \\
\hline Strategy FE & no & no & yes & yes & no & no & yes & yes \\
\hline$R^{2}$ & 0.011 & 0.025 & 0.021 & 0.036 & 0.011 & 0.019 & 0.022 & 0.032 \\
\hline
\end{tabular}

This table shows panel regressions of the form

$$
\begin{aligned}
& \text { Panel A: } r_{t \rightarrow t+4}^{s}=\mu_{s}+\beta \cdot \kappa_{t}^{s}+\varepsilon_{t \rightarrow t+4}^{s}, \\
& \text { Panel B: } Z_{t \rightarrow t+12}^{s}=\alpha_{s}+\beta \cdot \kappa_{t}^{s}+\varepsilon_{t \rightarrow t+12}^{s}, \\
& \text { Panel C: } \Delta \kappa_{t}^{s}=\alpha_{s}+\beta \cdot r_{t-1}^{s}+\varepsilon_{t}^{s}, \\
& \text { Panel D: } \Delta \kappa_{t}^{s}=\alpha_{s}+\psi \cdot \Delta \sigma_{t-1}^{s}+\tau \cdot \Delta \sigma_{t-1}^{M K T R F}+\lambda \cdot \Delta T E D_{t-1}+\varepsilon_{t}^{s} \text {, and } \\
& \text { Panel E: } r_{t \rightarrow t+4}^{s}=\mu_{s}+\varphi \cdot\left(\kappa_{t}^{s}-\kappa_{t-4}^{s}\right)+\varepsilon_{t \rightarrow t+4}^{s}
\end{aligned}
$$

for five strategies: value, momentum, accruals, net share issuance, and PEADs. $\kappa_{t}^{S}$ denotes the coefficient on the decile 1 dummy for strategy $s$ from our cross-sectional short interest regressions for all stocks at time $t$. The Internet Appendix provides more detail on our strategy capital estimates from accruals, net share issuance, and PEADs. $r_{t-1}^{S}$ is the return to strategy $s$ at time $t-1 . \sigma_{t-1}^{s}$ is the standard deviation of daily factor returns from strategy $s$ during quarter $t . r_{t \rightarrow t+4}^{S}$ is the four-quarter annual return for strategy $s$ from quarter $t$ to quarter $t+4 . Z_{t \rightarrow t+12}^{S}$ is amount of time that elapses (in years) before the postformation cumulative returns to holding the portfolio for strategy $s$ formed at time $t$ turns negative. The $t$-statistics in Panels A, B, and E are computed using Driscoll-Kraay (1998) standard errors (i.e., the panel analog of Newey-West (1987) standard errors) and allowing for serial correlation at up to six quarters. $t$ statistics in Panels C and D are computed using standard errors that cluster by quarter. We show results based on capital measures for all stocks from 1988 to 2011 and all stocks from 1988 to 2007. 
Table 3

Panel results (continued)

\begin{tabular}{|c|c|c|c|c|c|c|c|c|}
\hline & \multicolumn{4}{|c|}{$1988-2011$} & \multicolumn{4}{|c|}{$1988-2007$} \\
\hline & (1) & $(2)$ & (3) & (4) & (5) & (6) & (7) & (8) \\
\hline \multicolumn{9}{|c|}{ Panel C: The effect of past strategy returns on strategy-level capital flows } \\
\hline$r_{t-1}^{S}$ & $\begin{array}{c}-0.278 \\
{[-1.70]}\end{array}$ & $\begin{array}{c}-0.201 \\
{[-1.11]}\end{array}$ & $\begin{array}{c}-0.270 \\
{[-1.64]}\end{array}$ & $\begin{array}{l}-0.191 \\
{[-1.05]}\end{array}$ & $\begin{array}{l}-0.090 \\
{[-0.60]}\end{array}$ & $\begin{array}{c}0.057 \\
{[0.31]}\end{array}$ & $\begin{array}{l}-0.096 \\
{[-0.62]}\end{array}$ & $\begin{array}{r}0.054 \\
{[0.28]}\end{array}$ \\
\hline$M K T R F_{t-1}$ & & $\begin{array}{r}0.199 \\
{[1.30]}\end{array}$ & & $\begin{array}{c}0.201 \\
{[1.31]}\end{array}$ & & $\begin{array}{c}0.332 \\
{[1.95]}\end{array}$ & & $\begin{array}{r}0.331 \\
{[1.93]}\end{array}$ \\
\hline Constant & $\begin{array}{r}1.280 \\
{[1.06]}\end{array}$ & $\begin{array}{c}0.855 \\
{[0.66]}\end{array}$ & $\begin{array}{l}1.268 \\
{[1.05]}\end{array}$ & $\begin{array}{r}0.836 \\
{[0.65]}\end{array}$ & $\begin{array}{r}0.825 \\
{[0.71]}\end{array}$ & $\begin{array}{l}-0.106 \\
{[-0.08]}\end{array}$ & $\begin{array}{c}0.834 \\
{[0.72]}\end{array}$ & $\begin{array}{l}-0.099 \\
{[-0.08]}\end{array}$ \\
\hline$N$ & 465 & 465 & 465 & 465 & 385 & 385 & 385 & 385 \\
\hline Strategy FE & no & no & yes & yes & no & no & yes & yes \\
\hline$R^{2}$ & 0.005 & 0.009 & 0.006 & 0.010 & 0.001 & 0.012 & 0.002 & 0.013 \\
\hline \multicolumn{9}{|c|}{ Panel D: The effect of strategy volatility on strategy-level capital flows } \\
\hline$\Delta \sigma_{t-1}^{S}$ & $\begin{array}{l}-0.976 \\
{[-2.39]}\end{array}$ & $\begin{array}{c}-0.941 \\
{[-2.06]}\end{array}$ & $\begin{array}{r}-0.978 \\
{[-2.38]}\end{array}$ & $\begin{array}{l}-0.944 \\
{[-2.06]}\end{array}$ & $\begin{array}{l}-0.383 \\
{[-0.93]}\end{array}$ & $\begin{array}{r}0.055 \\
{[0.11]}\end{array}$ & $\begin{array}{l}-0.384 \\
{[-0.93]}\end{array}$ & $\begin{array}{r}0.053 \\
{[0.11]}\end{array}$ \\
\hline$\Delta \sigma_{t-1}^{M K T R F}$ & & $\begin{array}{l}-0.077 \\
{[-0.33]}\end{array}$ & & $\begin{array}{l}-0.076 \\
{[-0.33]}\end{array}$ & & $\begin{array}{c}-0.522 \\
{[-1.89]}\end{array}$ & & $\begin{array}{l}-0.521 \\
{[-1.88]}\end{array}$ \\
\hline$\Delta T E D_{t-1}$ & & $\begin{array}{c}0.027 \\
{[0.71]}\end{array}$ & & $\begin{array}{c}0.027 \\
{[0.70]}\end{array}$ & & $\begin{array}{l}-0.035 \\
{[-0.58]}\end{array}$ & & $\begin{array}{l}-0.035 \\
{[-0.58]}\end{array}$ \\
\hline Constant & $\begin{array}{r}0.830 \\
{[0.78]}\end{array}$ & $\begin{array}{r}0.876 \\
{[0.81]}\end{array}$ & $\begin{array}{r}0.831 \\
{[0.78]}\end{array}$ & $\begin{array}{r}0.876 \\
{[0.80]} \\
\end{array}$ & $\begin{array}{r}0.588 \\
{[0.55]}\end{array}$ & $\begin{array}{c}0.623 \\
{[0.59]}\end{array}$ & $\begin{array}{r}0.588 \\
{[0.54]}\end{array}$ & $\begin{array}{r}0.623 \\
{[0.58]}\end{array}$ \\
\hline$N$ & 460 & 460 & 460 & 460 & 380 & 380 & 380 & 380 \\
\hline Strategy FE & no & no & yes & yes & no & no & yes & yes \\
\hline$R^{2}$ & 0.020 & 0.021 & 0.021 & 0.022 & 0.003 & 0.013 & 0.004 & 0.014 \\
\hline \multicolumn{9}{|c|}{ Panel E: The relationship between arbitrage capital flows and future strategy returns } \\
\hline$\kappa_{t}^{S}-\kappa_{t-4}^{S}$ & $\begin{array}{c}0.000 \\
{[0.00]}\end{array}$ & $\begin{array}{c}0.001 \\
{[0.02]}\end{array}$ & $\begin{array}{c}0.004 \\
{[0.13]}\end{array}$ & $\begin{array}{c}0.005 \\
{[0.17]}\end{array}$ & $\begin{array}{r}-0.046 \\
{[-1.69]}\end{array}$ & $\begin{array}{r}-0.045 \\
{[-1.58]}\end{array}$ & $\begin{array}{l}-0.046 \\
{[-2.27]}\end{array}$ & $\begin{array}{l}-0.044 \\
{[-2.01]}\end{array}$ \\
\hline$r_{t-4 \rightarrow t}^{S}$ & & $\begin{array}{r}-0.086 \\
{[-0.86]}\end{array}$ & & $\begin{array}{l}-0.123 \\
{[-1.22]}\end{array}$ & & $\begin{array}{l}-0.067 \\
{[-0.51]}\end{array}$ & & $\begin{array}{l}-0.132 \\
{[-1.05]}\end{array}$ \\
\hline Constant & $\begin{array}{r}6.270 \\
{[4.15]}\end{array}$ & $\begin{array}{r}6.840 \\
{[3.72]} \\
\end{array}$ & $\begin{array}{r}6.259 \\
{[4.14]} \\
\end{array}$ & $\begin{array}{c}7.072 \\
{[3.78]}\end{array}$ & $\begin{array}{r}7.969 \\
{[6.16]}\end{array}$ & $\begin{array}{c}8.487 \\
{[4.01]}\end{array}$ & $\begin{array}{c}7.970 \\
{[6.14]}\end{array}$ & $\begin{array}{r}8.988 \\
{[4.40]}\end{array}$ \\
\hline$N$ & 440 & 440 & 440 & 440 & 370 & 370 & 370 & 370 \\
\hline Strategy FE & no & no & yes & yes & no & no & yes & yes \\
\hline$R^{2}$ & 0.000 & 0.008 & 0.027 & 0.042 & 0.009 & 0.014 & 0.067 & 0.083 \\
\hline
\end{tabular}


Table 4

The level of arbitrage capital and the decay of strategy profits following portfolio formation

\begin{tabular}{|c|c|c|c|c|c|c|c|c|c|c|c|c|}
\hline & \multicolumn{6}{|c|}{ Value } & \multicolumn{6}{|c|}{ Momentum } \\
\hline & \multicolumn{2}{|c|}{$\begin{array}{l}\text { All stocks, } \\
1988-2011\end{array}$} & \multicolumn{2}{|c|}{$\begin{array}{l}\text { All stocks, } \\
1988-2008\end{array}$} & \multicolumn{2}{|c|}{$\begin{array}{c}\text { NYSE and AMEX, } \\
1973-2011 \\
\end{array}$} & \multicolumn{2}{|c|}{$\begin{array}{l}\text { All stocks, } \\
1988-2011\end{array}$} & \multicolumn{2}{|c|}{$\begin{array}{l}\text { All stocks, } \\
1988-2008\end{array}$} & \multicolumn{2}{|c|}{$\begin{array}{c}\text { NYSE and AMEX, } \\
1973-2011 \\
\end{array}$} \\
\hline & (1) & $\overline{(2)}$ & (3) & $\overline{(4)}$ & (5) & (6) & (7) & (8) & (9) & $\overline{(10)}$ & (11) & (12) \\
\hline$\kappa_{t}^{S}$ & $\begin{array}{l}-0.057 \\
{[-0.51]}\end{array}$ & $\begin{array}{l}-0.308 \\
{[-0.97]}\end{array}$ & $\begin{array}{r}-0.039 \\
{[-0.23]}\end{array}$ & $\begin{array}{r}-0.453 \\
{[-1.26]}\end{array}$ & $\begin{array}{l}-0.624 \\
{[-3.38]}\end{array}$ & $\begin{array}{l}-0.542 \\
{[-2.92]}\end{array}$ & $\begin{array}{r}-0.322 \\
{[-1.12]}\end{array}$ & $\begin{array}{r}0.022 \\
{[0.08]}\end{array}$ & $\begin{array}{l}-0.659 \\
{[-2.21]}\end{array}$ & $\begin{array}{l}-0.286 \\
{[-0.94]}\end{array}$ & $\begin{array}{l}-0.171 \\
{[-1.22]}\end{array}$ & $\begin{array}{l}-0.037 \\
{[-0.20]}\end{array}$ \\
\hline Trend & & $\begin{array}{r}0.548 \\
{[0.88]}\end{array}$ & & $\begin{array}{r}0.918 \\
{[1.63]}\end{array}$ & & $\begin{array}{l}-0.167 \\
{[-0.49]}\end{array}$ & & $\begin{array}{l}-0.820 \\
{[-4.19]}\end{array}$ & & $\begin{array}{l}-0.959 \\
{[-4.10]}\end{array}$ & & $\begin{array}{l}-0.382 \\
{[-1.57]}\end{array}$ \\
\hline Constant & $\begin{array}{r}0.679 \\
{[4.44]} \\
\end{array}$ & $\begin{array}{r}0.681 \\
{[4.81]} \\
\end{array}$ & $\begin{array}{r}0.675 \\
{[3.95]}\end{array}$ & $\begin{array}{r}0.676 \\
{[3.74]} \\
\end{array}$ & $\begin{array}{r}1.089 \\
{[7.23]}\end{array}$ & $\begin{array}{r}1.131 \\
{[5.60]}\end{array}$ & $\begin{array}{r}0.967 \\
{[4.92]} \\
\end{array}$ & $\begin{array}{c}1.222 \\
{[8.26]}\end{array}$ & $\begin{array}{l}1.112 \\
{[5.72]}\end{array}$ & $\begin{array}{l}1.359 \\
{[9.10]} \\
\end{array}$ & $\begin{array}{r}0.911 \\
{[10.01]} \\
\end{array}$ & $\begin{array}{r}1.059 \\
{[8.16]}\end{array}$ \\
\hline$T$ & 93 & 93 & 78 & 78 & 155 & 155 & 94 & 94 & 78 & 78 & 156 & 156 \\
\hline$R^{2}$ & 0.001 & 0.006 & 0 & 0.016 & 0.047 & 0.048 & 0.019 & 0.078 & 0.064 & 0.121 & 0.006 & 0.018 \\
\hline
\end{tabular}

This table shows time-series regressions of the form

$$
Z_{t \rightarrow t+12}^{s}=\alpha+\beta \cdot \kappa_{t}^{s}+\varepsilon_{t \rightarrow t+12}^{s}
$$

for value and momentum, where $\kappa_{t}^{S}$ denotes the coefficient on the decile 1 dummy for strategy $s$ from our cross-sectional short interest regressions at time $t$. For each portfolio formation date, we count the amount of time that subsequently elapses (in years) before the postformation cumulative returns to holding this portfolio turn negative, $Z_{t \rightarrow t+12}^{S}$. We wait one month (twenty trading days) following portfolio formation before asking how long cumulative portfolio returns take to turn negative. If cumulative returns are still positive after twelve quarters, this variable is top-coded at three years. $t$-statistics are shown in brackets and are computed using Newey-West (1987) standard errors allowing for serial correlation at up to eighteen quarterly lags. We show results based on capital measures for all stocks from 1988Q3 to 2011Q3, all stocks from 1988Q3 to 2007Q4, and NYSE and AMEX stocks only from 1973Q1 to 2011Q3. 
Table 5

The effect of past strategy returns on strategy-level capital flows

\begin{tabular}{|c|c|c|c|c|c|c|c|c|c|c|c|c|}
\hline & \multicolumn{6}{|c|}{ Value } & \multicolumn{6}{|c|}{ Momentum } \\
\hline & \multicolumn{2}{|c|}{$\begin{array}{l}\text { All stocks, } \\
1988-2011\end{array}$} & \multicolumn{2}{|c|}{$\begin{array}{l}\text { All stocks, } \\
1988-2008\end{array}$} & \multicolumn{2}{|c|}{$\begin{array}{c}\text { NYSE and AMEX, } \\
1973-2011 \\
\end{array}$} & \multicolumn{2}{|c|}{$\begin{array}{l}\text { All stocks, } \\
1988-2011\end{array}$} & \multicolumn{2}{|c|}{$\begin{array}{l}\text { All stocks, } \\
1988-2008\end{array}$} & \multicolumn{2}{|c|}{$\begin{array}{c}\text { NYSE and AMEX, } \\
1973-2011\end{array}$} \\
\hline & (1) & (2) & (3) & (4) & (5) & (6) & (7) & $\overline{(8)}$ & (9) & $\overline{(10)}$ & (11) & $(12)$ \\
\hline$r_{t-1}^{s}$ & $\begin{array}{r}-0.493 \\
{[-1.46]}\end{array}$ & $\begin{array}{l}-0.624 \\
{[-1.65]}\end{array}$ & $\begin{array}{r}-0.321 \\
{[-1.03]}\end{array}$ & $\begin{array}{l}-0.475 \\
{[-1.30]}\end{array}$ & $\begin{array}{l}-0.353 \\
{[-1.16]}\end{array}$ & $\begin{array}{l}-0.578 \\
{[-1.63]}\end{array}$ & $\begin{array}{c}0.162 \\
{[0.43]}\end{array}$ & $\begin{array}{r}0.403 \\
{[1.11]}\end{array}$ & $\begin{array}{c}0.672 \\
{[2.12]}\end{array}$ & $\begin{array}{r}0.831 \\
{[2.56]}\end{array}$ & $\begin{array}{r}0.267 \\
{[0.66]}\end{array}$ & $\begin{array}{r}0.432 \\
{[1.12]}\end{array}$ \\
\hline$M K T R F_{t-1}$ & & $\begin{array}{l}-0.410 \\
{[-1.28]}\end{array}$ & & $\begin{array}{l}-0.251 \\
{[-0.65]}\end{array}$ & & $\begin{array}{l}-0.466 \\
{[-1.69]}\end{array}$ & & $\begin{array}{r}0.823 \\
{[2.07]}\end{array}$ & & $\begin{array}{l}0.560 \\
{[1.65]}\end{array}$ & & $\begin{array}{r}0.624 \\
{[2.17]}\end{array}$ \\
\hline Constant & $\begin{array}{l}2.601 \\
{[1.16]}\end{array}$ & $\begin{array}{l}3.328 \\
{[1.35]}\end{array}$ & $\begin{array}{r}1.821 \\
{[0.82]}\end{array}$ & $\begin{array}{r}2.477 \\
{[0.97]}\end{array}$ & $\begin{array}{c}1.647 \\
{[0.81]}\end{array}$ & $\begin{array}{l}2.552 \\
{[1.18]}\end{array}$ & $\begin{array}{r}0.917 \\
{[0.26]}\end{array}$ & $\begin{array}{l}-0.822 \\
{[-0.23]}\end{array}$ & $\begin{array}{c}-0.512 \\
{[-0.16]}\end{array}$ & $\begin{array}{l}-2.044 \\
{[-0.60]}\end{array}$ & $\begin{array}{r}0.117 \\
{[0.04]}\end{array}$ & $\begin{array}{l}-1.073 \\
{[-0.37]}\end{array}$ \\
\hline$T$ & 93 & 93 & 77 & 77 & 155 & 155 & 93 & 93 & 77 & 77 & 155 & 155 \\
\hline$R^{2}$ & 0.022 & 0.047 & 0.011 & 0.018 & 0.008 & 0.034 & 0.002 & 0.048 & 0.039 & 0.064 & 0.005 & 0.032 \\
\hline
\end{tabular}

This table shows time-series regressions of the form

$$
\Delta \kappa_{t}^{s}=\alpha+\beta \cdot r_{t-1}^{s}+\varepsilon_{t}^{s}
$$

for value and momentum where $\kappa_{t}^{s}$ denotes the coefficient on the decile 1 dummy for strategy $s$ from our cross-sectional short interest regressions at time $t$ and $r_{t-1}^{S}$ is the return to strategy $s$ at time $t-1$. $t$-statistics are shown in brackets and are computed using heteroscedasticity-robust standard errors. We show results based on capital measures for all stocks from 1988Q4 to 2011Q4, all stocks from 1988Q4 to 2007Q4, and NYSE and AMEX stocks only from 1973Q2 to 2011Q4. 
Table 6

Investigating contagion: The effect of other strategy returns on momentum capital flows

\begin{tabular}{|c|c|c|c|c|c|c|c|c|}
\hline & \multicolumn{4}{|c|}{ 1988-2011 } & \multicolumn{4}{|c|}{ 1988-2007 } \\
\hline & (1) & (2) & (3) & (4) & (5) & (6) & (7) & (8) \\
\hline$U M D_{t-1}$ & $\begin{array}{c}0.162 \\
{[0.43]}\end{array}$ & $\begin{array}{r}0.403 \\
{[1.11]}\end{array}$ & $\begin{array}{c}0.263 \\
{[0.76]}\end{array}$ & $\begin{array}{c}0.095 \\
{[0.25]}\end{array}$ & $\begin{array}{c}0.672 \\
{[2.12]}\end{array}$ & $\begin{array}{c}0.831 \\
{[2.56]}\end{array}$ & $\begin{array}{c}0.710 \\
{[2.60]}\end{array}$ & $\begin{array}{r}0.368 \\
{[1.14]}\end{array}$ \\
\hline$M K T R F_{t-1}$ & & $\begin{array}{r}0.823 \\
{[2.07]}\end{array}$ & & $\begin{array}{l}-0.709 \\
{[-0.99]}\end{array}$ & & $\begin{array}{r}0.560 \\
{[1.65]}\end{array}$ & & $\begin{array}{l}-1.225 \\
{[-2.40]}\end{array}$ \\
\hline$E H E D G E_{t-1}$ & & & $\begin{array}{r}1.799 \\
{[3.24]}\end{array}$ & $\begin{array}{c}2.664 \\
{[2.55]}\end{array}$ & & & $\begin{array}{r}1.816 \\
{[3.81]}\end{array}$ & $\begin{array}{r}3.286 \\
{[3.74]}\end{array}$ \\
\hline Constant & $\begin{array}{c}0.917 \\
{[0.26]}\end{array}$ & $\begin{array}{c}-0.822 \\
{[-0.23]}\end{array}$ & $\begin{array}{l}-4.976 \\
{[-1.16]}\end{array}$ & $\begin{array}{l}-6.453 \\
{[-1.30]}\end{array}$ & $\begin{array}{l}-0.512 \\
{[-0.16]}\end{array}$ & $\begin{array}{l}-2.044 \\
{[-0.60]}\end{array}$ & $\begin{array}{l}-7.721 \\
{[-1.96]}\end{array}$ & $\begin{array}{r}-10.464 \\
{[-2.55]}\end{array}$ \\
\hline$T$ & 93 & 93 & 87 & 87 & 77 & 77 & 71 & 71 \\
\hline$R^{2}$ & 0.002 & 0.048 & 0.103 & 0.113 & 0.039 & 0.064 & 0.158 & 0.200 \\
\hline
\end{tabular}

This table shows time-series regressions of the form

$$
\Delta \kappa_{t}^{M O M}=\alpha+\gamma \cdot r_{t-1}^{A}+\beta \cdot U M D_{t-1}+\varepsilon_{t}^{M O M},
$$

where $r_{t-1}^{A}$ is the lagged quarterly return on some other strategy $A$. EHEGDE $E_{t-1}$ is the lagged quarterly return on on HFR's Equity Hedge index. $t$-statistics are shown in brackets and are computed using heteroscedasticity-robust standard errors. We show results based on capital measures for all stocks from 1988Q4 to 2011Q4 and all stocks from 1988Q4 to 2007Q4. We lose six observations in Columns (3), (4), (7), and (8) because $E H E G D E_{t-1}$ is only available beginning in 1990Q2. 
Table 7

The effect of strategy volatility and intermediary funding liquidity on strategy-level capital flows

\begin{tabular}{|c|c|c|c|c|c|c|c|c|c|c|c|c|}
\hline & \multicolumn{6}{|c|}{ Value } & \multicolumn{6}{|c|}{ Momentum } \\
\hline & \multicolumn{2}{|c|}{$\begin{array}{l}\text { All stocks, } \\
1988-2011\end{array}$} & \multicolumn{2}{|c|}{$\begin{array}{l}\text { All stocks, } \\
1988-2008\end{array}$} & \multicolumn{2}{|c|}{$\begin{array}{c}\text { NYSE and AMEX, } \\
1973-2011 \\
\end{array}$} & \multicolumn{2}{|c|}{$\begin{array}{l}\text { All stocks, } \\
1988-2011\end{array}$} & \multicolumn{2}{|c|}{$\begin{array}{l}\text { All stocks, } \\
\text { 1988-2008 }\end{array}$} & \multicolumn{2}{|c|}{$\begin{array}{c}\text { NYSE and AMEX } \\
1973-2011 \\
\end{array}$} \\
\hline & $(1)$ & $(2)$ & (3) & $(4)$ & (5) & $(6)$ & (7) & (8) & (9) & $(10)$ & $(11)$ & $(12)$ \\
\hline$\Delta \sigma_{t-1}^{S}$ & $\begin{array}{l}-2.239 \\
{[-4.15]}\end{array}$ & $\begin{array}{l}-3.153 \\
{[-5.62]}\end{array}$ & $\begin{array}{l}-2.970 \\
{[-3.99]}\end{array}$ & $\begin{array}{l}-3.338 \\
{[-3.17]}\end{array}$ & $\begin{array}{r}-1.73 \\
{[-1.96]}\end{array}$ & $\begin{array}{l}-3.696 \\
{[-4.31]}\end{array}$ & $\begin{array}{l}-0.840 \\
{[-0.87]}\end{array}$ & $\begin{array}{l}-1.012 \\
{[-1.20]}\end{array}$ & $\begin{array}{c}0.392 \\
{[0.50]}\end{array}$ & $\begin{array}{r}0.956 \\
{[1.38]}\end{array}$ & $\begin{array}{l}-1.426 \\
{[-1.40]}\end{array}$ & $\begin{array}{l}-1.112 \\
{[-0.96]}\end{array}$ \\
\hline$\Delta \sigma_{t-1}^{M K T R F}$ & & $\begin{array}{c}0.666 \\
{[1.29]}\end{array}$ & & $\begin{array}{c}0.313 \\
{[0.41]}\end{array}$ & & $\begin{array}{r}1.42 \\
{[4.06]}\end{array}$ & & $\begin{array}{c}0.716 \\
{[1.30]}\end{array}$ & & $\begin{array}{c}-0.291 \\
{[-0.53]}\end{array}$ & & $\begin{array}{l}-0.296 \\
{[-0.65]}\end{array}$ \\
\hline$\Delta T E D_{t-1}$ & & $\begin{array}{r}0.156 \\
{[1.72]}\end{array}$ & & $\begin{array}{r}0.129 \\
{[1.24]}\end{array}$ & & $\begin{array}{l}-0.025 \\
{[-0.91]}\end{array}$ & & $\begin{array}{c}-0.412 \\
{[-3.53]}\end{array}$ & & $\begin{array}{l}-0.499 \\
{[-3.11]}\end{array}$ & & $\begin{array}{l}-0.044 \\
{[-1.37]}\end{array}$ \\
\hline Constant & $\begin{array}{r}2.308 \\
{[1.08]}\end{array}$ & $\begin{array}{l}2.355 \\
{[1.20]}\end{array}$ & $\begin{array}{l}1.447 \\
{[0.70]}\end{array}$ & $\begin{array}{c}1.442 \\
{[0.70]}\end{array}$ & $\begin{array}{r}1.168 \\
{[0.60]}\end{array}$ & $\begin{array}{c}0.992 \\
{[0.53]}\end{array}$ & $\begin{array}{r}1.370 \\
{[0.42]}\end{array}$ & $\begin{array}{r}0.783 \\
{[0.25]}\end{array}$ & $\begin{array}{r}1.280 \\
{[0.43]}\end{array}$ & $\begin{array}{l}1.176 \\
{[0.41]}\end{array}$ & $\begin{array}{c}0.717 \\
{[0.27]}\end{array}$ & $\begin{array}{r}0.706 \\
{[0.27]}\end{array}$ \\
\hline$T$ & 92 & 92 & 76 & 76 & 154 & 154 & 92 & 92 & 76 & 76 & 154 & 154 \\
\hline$R^{2}$ & 0.117 & 0.263 & 0.162 & 0.181 & 0.043 & 0.14 & 0.020 & 0.141 & 0.004 & 0.116 & 0.042 & 0.052 \\
\hline
\end{tabular}

This table shows time-series regressions of the form

$$
\Delta \kappa_{t}^{s}=\alpha+\psi \cdot \Delta \sigma_{t-1}^{s}+\tau \cdot \Delta \sigma_{t-1}^{M K T R F}+\lambda \cdot \Delta T E D_{t-1}+\varepsilon_{t}^{s}
$$

for value and momentum. $\sigma_{t-1}^{s}$ is the standard deviation of daily factor returns from strategy $s$ during quarter $t$. The quarterly returns are in percentages and factor volatility measures are in annualized percentages. We measure the TED spread using the difference between the rate on threemonth Eurodollar deposits (i.e., 3-month LIBOR) and the yield on the three-month Treasury bill. Both rates are taken from the Federal Reserve H.15 release. $t$-statistics are shown in brackets and are computed using heteroscedasticity-robust standard errors. We show results based on capital measures for all stocks from 1988Q4 to 2011Q4, all stocks from 1988Q4 to 2007Q4, and NYSE and AMEX stocks only from 1973Q2 to 2011Q4. 
Table 8

The relationship between arbitrage capital flows and future strategy returns

\begin{tabular}{|c|c|c|c|c|c|c|c|c|c|c|c|c|}
\hline & \multicolumn{6}{|c|}{ Value } & \multicolumn{6}{|c|}{ Momentum } \\
\hline & \multicolumn{2}{|c|}{$\begin{array}{l}\text { All stocks, } \\
1988-2011\end{array}$} & \multicolumn{2}{|c|}{$\begin{array}{l}\text { All stocks, } \\
1988-2008\end{array}$} & \multicolumn{2}{|c|}{$\begin{array}{c}\text { NYSE and AMEX, } \\
1973-2011 \\
\end{array}$} & \multicolumn{2}{|c|}{$\begin{array}{l}\text { All stocks, } \\
1988-2011\end{array}$} & \multicolumn{2}{|c|}{$\begin{array}{l}\text { All stocks, } \\
1988-2008\end{array}$} & \multicolumn{2}{|c|}{$\begin{array}{c}\text { NYSE and AMEX } \\
1973-2011\end{array}$} \\
\hline & (1) & $\overline{(2)}$ & (3) & (4) & (5) & (6) & (7) & (8) & (9) & $\overline{(10)}$ & (11) & (12) \\
\hline$\kappa_{t}^{S}-\kappa_{t-4}^{S}$ & $\begin{array}{c}-0.122 \\
{[-2.26]}\end{array}$ & $\begin{array}{c}-0.124 \\
{[-2.31]}\end{array}$ & $\begin{array}{r}-0.140 \\
{[-2.59]}\end{array}$ & $\begin{array}{c}-0.146 \\
{[-3.10]}\end{array}$ & $\begin{array}{c}-0.124 \\
{[-4.31]}\end{array}$ & $\begin{array}{c}-0.102 \\
{[-3.77]}\end{array}$ & $\begin{array}{c}0.031 \\
{[0.34]}\end{array}$ & $\begin{array}{r}0.034 \\
{[0.38]}\end{array}$ & $\begin{array}{c}-0.114 \\
{[-2.21]}\end{array}$ & $\begin{array}{l}-0.092 \\
{[-2.14]}\end{array}$ & $\begin{array}{c}0.002 \\
{[0.03]}\end{array}$ & $\begin{array}{r}0.009 \\
{[0.14]}\end{array}$ \\
\hline$V S_{t}$ & & $\begin{array}{r}0.187 \\
{[1.99]}\end{array}$ & & $\begin{array}{r}0.279 \\
{[2.11]}\end{array}$ & & $\begin{array}{c}0.092 \\
{[2.39]}\end{array}$ & & & & & & \\
\hline$r_{t-4 \rightarrow t}^{S}$ & & $\begin{array}{l}-0.052 \\
{[-0.30]}\end{array}$ & & $\begin{array}{l}-0.105 \\
{[-0.52]}\end{array}$ & & $\begin{array}{l}-0.093 \\
{[-0.75]}\end{array}$ & & $\begin{array}{l}-0.219 \\
{[-1.64]}\end{array}$ & & $\begin{array}{l}-0.272 \\
{[-2.11]}\end{array}$ & & $\begin{array}{l}-0.216 \\
{[-2.02]}\end{array}$ \\
\hline Constant & $\begin{array}{r}4.243 \\
{[1.43]}\end{array}$ & $\begin{array}{r}-13.904 \\
{[-1.74]}\end{array}$ & $\begin{array}{l}5.690 \\
{[1.75]}\end{array}$ & $\begin{array}{r}-20.115 \\
{[-1.80]}\end{array}$ & $\begin{array}{r}4.823 \\
{[2.55]}\end{array}$ & $\begin{array}{l}-5.126 \\
{[-1.16]}\end{array}$ & $\begin{array}{r}7.527 \\
{[2.24]}\end{array}$ & $\begin{array}{r}9.369 \\
{[2.39]}\end{array}$ & $\begin{array}{r}11.708 \\
{[4.34]}\end{array}$ & $\begin{array}{r}14.535 \\
{[4.59]}\end{array}$ & $\begin{array}{r}8.345 \\
{[3.60]}\end{array}$ & $\begin{array}{r}10.198 \\
{[3.87]}\end{array}$ \\
\hline$T$ & 88 & 88 & 74 & 74 & 150 & 150 & 88 & 88 & 74 & 74 & 150 & 150 \\
\hline$R^{2}$ & 0.047 & 0.157 & 0.059 & 0.224 & 0.079 & 0.138 & 0.005 & 0.053 & 0.070 & 0.138 & 0.000 & 0.047 \\
\hline
\end{tabular}

This table shows time-series forecasting regressions of the form

$$
r_{t \rightarrow t+4}^{s}=\mu+\varphi \cdot\left(\kappa_{t}^{s}-\kappa_{t-4}^{s}\right)+\varepsilon_{t \rightarrow t+4}^{s},
$$

where $r_{t \rightarrow t+4}^{S}$ is the four-quarter annual return from quarter $t$ to quarter $t+4 . V S_{t}$ is the value spread computed as in Cohen, Polk, and Vuolteenaho (2003). $t$-statistics are shown in brackets and are computed using Newey-West (1987) standard errors and allowing for serial correlation at up to six lags. We show results based on capital measures for all stocks from 1989Q3 to 2011Q2, all stocks from 1989Q3 to 2007Q4, and NYSE and AMEX stocks from 1974Q1 to 2011Q2. 